Portland State University

PDXScholar

$11-7-1996$

\title{
Undergraduate Student Satisfaction with the Sociology Program at Portland State University
}

Katherine Sullivan

Portland State University

Follow this and additional works at: https://pdxscholar.library.pdx.edu/open_access_etds

Part of the Sociology Commons

Let us know how access to this document benefits you.

\section{Recommended Citation}

Sullivan, Katherine, "Undergraduate Student Satisfaction with the Sociology Program at Portland State University" (1996). Dissertations and Theses. Paper 5104.

https://doi.org/10.15760/etd.6980

This Thesis is brought to you for free and open access. It has been accepted for inclusion in Dissertations and Theses by an authorized administrator of PDXScholar. Please contact us if we can make this document more accessible: pdxscholar@pdx.edu. 


\section{THESIS APPROVAL}

The abstract and thesis of Katherine Sullivan for the Master of Science in Sociology were presented on November $7^{\text {th }}, 1996$ and accepted by the thesis committee and the department.

Committee Approvals:

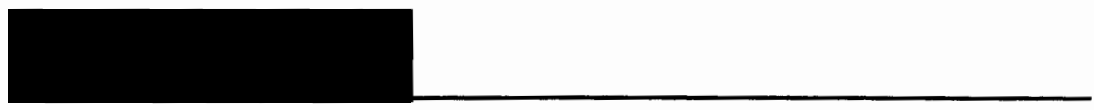

Grant M. Farr, Chair

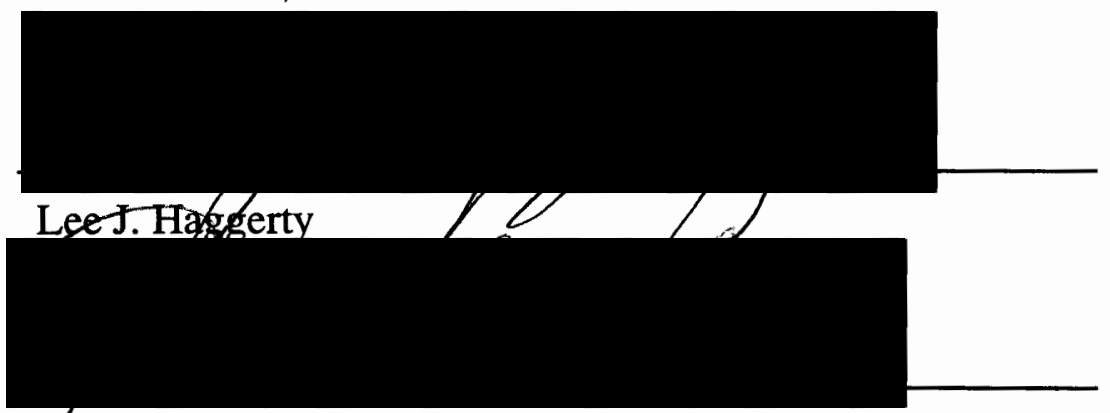

Robert C. Liebman

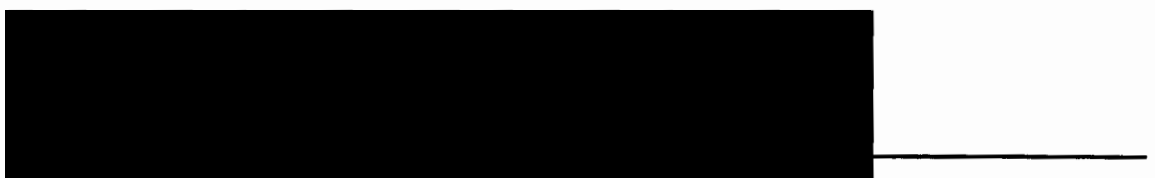

Mary K. Kinnick

Representative of the Office of Graduate Studies

Department Approval

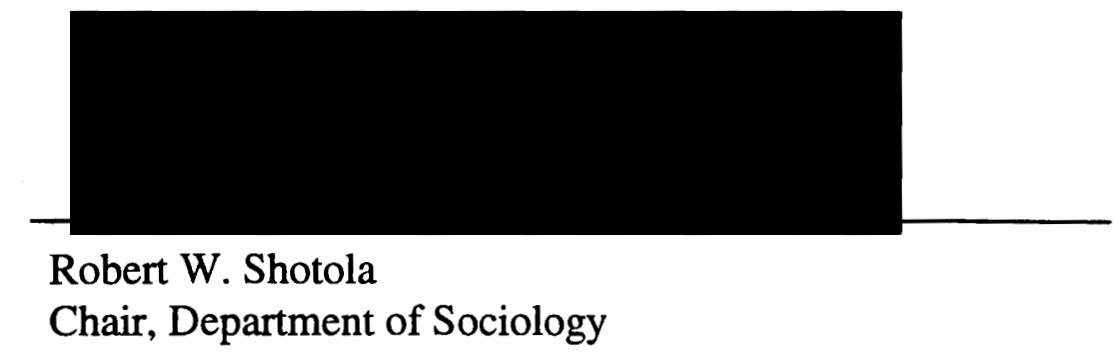

ACCEPTED FOR PORTLAND STATE UNIVERSITY BY THE LIBRARY

BY

ON 12 dlectinex 1996 
AN ABSTRACT OF THE THESIS OF Katherine Sullivan for the Master of Science in Sociology presented November $7^{\text {th }}, 1996$.

Title: Undergraduate Student Satisfaction with the Sociology Program at Portland State University

An examination of sociology student satisfaction levels is performed and an attempt is made to explain variations in degree program satisfaction. A comparison is made between current student and alumni regarding the coursework and experiences they feel should be offered in the undergraduate degree program in sociology at Portland State University (PSU). The study population consists of all PSU students who have obtained an undergraduate degree in sociology since the program's inception and all students currently attending PSU and majoring in sociology.

The typical respondent is female (the ratio of females to males being higher for current students than for alumni) and is 39 years old. Close to half of the respondents have at least one parent with a college degree. Most current students work while attending school. Current students earn less than alumni (they are also more likely to work part-time). Around half of the alumni respondents stop their educational career with their undergraduate degree. The majority of those who continued beyond the undergraduate level do so in a field outside of sociology. 
Alumni are predominantly employed in white collar jobs involving computers and writing -- skills they rank as important attributes of a good department. The majority of current students are full-time seniors who transferred from another institution, and chose to attend college to gain personal knowledge and to prepare for employment. When asked about their goals, the majority of current students intend to find employment in the six months after graduation.

Current students are more satisfied with the degree program than alumni respondents. Age is not related to a stronger vocational orientation. The level of financial hardship incurred by alumni to attend college is positively correlated with a vocational orientation. This was not the case for current students who show no relationship between the two variables.

Degree program satisfaction is positively correlated with job satisfaction, but the relationship is weak. The more vocationally oriented students and alumni are more satisfied with the degree program. Finally, the more useful the student feels sociology is in their present job, the more satisfied they are with the program. 


\title{
UNDERGRADUATE STUDENT SATISFACTION WITH THE
} SOCIOLOGY PROGRAM AT PORTLAND STATE UNIVERSITY

\author{
by
}

Katherine Sullivan

\begin{abstract}
A thesis submitted in partial fulfillment of the requirements for the degree of

Master of Science

in

Sociology
\end{abstract}

Portland State University

1996 


\section{TABle Of Contents}

\section{CHAPTER I}

\section{1}

\section{INTRODUCTION}

I. BACKGROUND

1

II. STATEMENT OF THE PROBLEM

6

III. LIMITATIONS

IV. SIGNIFICANCE

\section{CHAPTER II}

\section{REVIEW OF THE LITERATURE}

$\begin{array}{lll}\text { I. INTRODUCTION } & 10\end{array}$

II. PROFILE OF SOCIOLOGY MAJORS' 10

III. SOCIOLOGY AS A DISCIPLINE 16

IV. THE TEACHING OF SOCIOLOGY 24

V. THE MODEL $\quad 28$

VI. JOB SATISFACTION AND JOB/DEGREE CONGRUENCE 33

VII. VOCATIONAL/LIBERAL ARTS ORIENTATION

$\begin{array}{ll}\text { VIII. HYPOTHESES } & 37\end{array}$

\section{CHAPTER III}

PROCEDURES AND METHODOLOGY

$\begin{array}{lll}\text { I. INTRODUCTION } & 40\end{array}$

II. POPULATION $\quad 40$

III. DATA COLLECTION $\quad 43$

$\begin{array}{ll}\text { IV. STATISTICAL TREATMENT } & 46\end{array}$

\section{CHAPTER IV.}

\section{Presentation of Findings}

$\begin{array}{lll}\text { I. INTRODUCTION } & 48\end{array}$

II. PROFILE OF RESPONDENTS $\quad 48$

$\begin{array}{ll}\text { III. CONCLUSION } & 73\end{array}$ 
ANALYSIS

I. INTRODUCTION

II. MEASURING DEGREE PROGRAM SATISFACTION

$\begin{array}{ll}\text { III. } & 76\end{array}$

CHAPTER VI.

92

DISCUSSION AND RECOMMENDATIONS

$\begin{array}{ll}\text { I. INTRODUCTION } & 92\end{array}$

II. SUMMARY OF RESPONDENT INFORMATION

$\begin{array}{ll}\text { III. } & 93\end{array}$

III. DISCUSSION AND RECOMMENDATIONS $\quad 94$

IV. OTHER RECOMMENDATIONS 100

$\begin{array}{ll}\text { IV. RECOMMENDATIONS FOR FURTHER STUDY } & 102\end{array}$

SELECTED BIBLIOGRAPHY $\quad 105$

$\begin{array}{ll}\text { APPENDIX A } & 109\end{array}$

\begin{tabular}{lr} 
APPENDIX B & 117 \\
\hline
\end{tabular}

\begin{tabular}{lr} 
APPENDIX C & 121 \\
\hline
\end{tabular}

\begin{tabular}{lr} 
APPENDIX D & 126 \\
\hline
\end{tabular}

$\begin{array}{ll}\text { APPENDIX E } & 132\end{array}$

\begin{tabular}{ll} 
APPENDIX F & 133 \\
\hline
\end{tabular} 


\section{LIST OF FIGURES}

\section{ChAPTER I - INTRODUCTION}

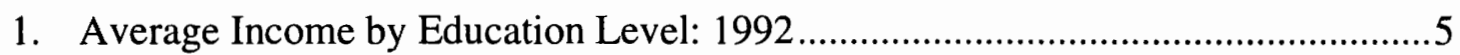

2. Unemployment Rates of Persons 25 Years Old and Over, by Highest Degree Obtained: 1993

\section{ChAPTER II - REVIEW Of THE Literature}

3. Undergraduate Degrees Awarded in Sociology from 1949-1993.

4. Trend of Undergraduate Degrees in Sociology Awarded Compared with Degrees Awarded in the Social Sciences: 1971-1993

\section{Chapter IV - Presentation of Findings}

5. Education Level of Mother and Father by Alumni/Current Status .........................51

6. National/PSU Sources of Employment for Sociology Majors..............................53

7. Personal Income for Current Students and Alumni ............................................55

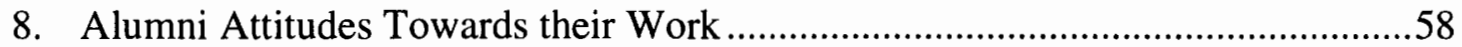

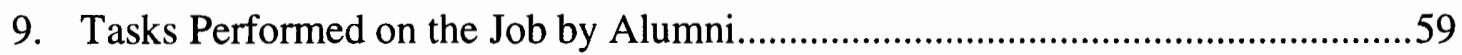

10. Sociology Courses Which Have Been Personally and Professionally Valuable to Alumni Since Graduation ................................................................................6

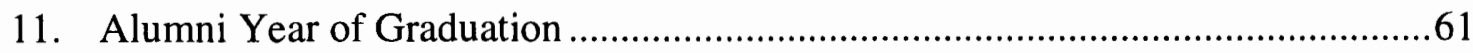

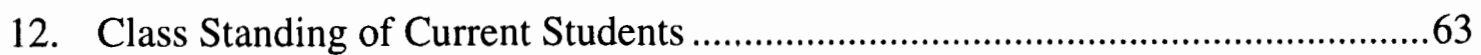




\section{Chapter IV - Presentation of Findings (Continued)}

13. Why Current Students Chose Sociology as Their Major........................................66

14. Courses Which Influenced Current Student's Decision to Major in Sociology ....67

15. Alumni and Current Student's Attitudes Towards the Department........................69

16. Liberal Arts Orientation Items - Comparison Between Alumni and Current

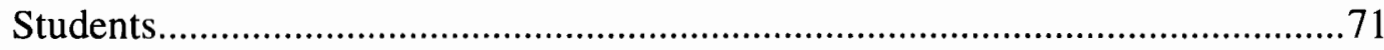

17. Vocationally Orientated Items - Comparison Between Alumni and Current

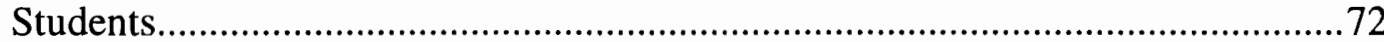

18 Most Important Component of a Sociology Undergraduate Program ....................73

\section{Chapter V - AnAlysis}

19. Degree Program Satisfaction Scores for Current Students and Alumni .................76

20. Comparison of Average Degree Program Satisfaction Scores for Alumni

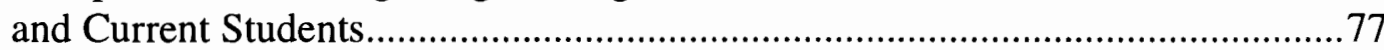

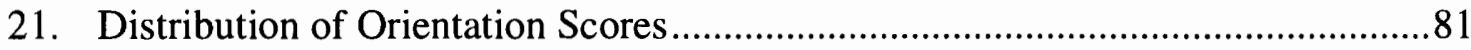

22. Comparison of Mean Orientation Scores by How the Majority of Tuition Was Paid

\section{Chapter VI - Discussion ANd Recommendations}

23. Summary of Hypotheses Testing .94 


\section{CHAPTER I}

\section{INTRODUCTION}

\section{Background}

The literature on the teaching of sociology does not reflect the importance of undergraduate training to academic departments and their students. Sociologist William Rau (1992) laments the lack of serious sociological studies on higher education and asks "[w]hy...have our most talented scholars ignored higher education?" (p.168). He claims there is a dearth of literature regarding undergraduate training and charges that the most prestigious journals have "completely ignore issues concerning teaching and undergraduates" (p.168).

Sociologists and educational researchers have essentially ignored the question of what undergraduates want and expect from their degree programs even though the majority of sociology undergraduates are employed full-time after graduation and do not go on to receive higher degrees. Despite this, there has been limited data compiled on the work experiences of sociology undergraduate alumni and the perceived relevance of sociology to their jobs 
(Paap and McMillin, 1990). In particular, the satisfaction level of students with their degree program has received insufficient attention in the literature. The 1993 General Education Working Group Report and Recommendations from Portland State University states:

It is often the case when faculty debate curricular requirements...we focus on the form and content of those requirements. Only rarely do we seek to examine what is known about the demand side of higher education as expressed through student expectations and aspirations....And rarely is it the case that curricular efforts include consideration of student characteristics and how those may effect the learning goals of curriculum structure, content, and delivery (p.22).

This void in understanding is significant considering the majority of most departments' funding derives from the role of training undergraduates -- both majors and non-majors.

The absence of a strong feedback loop between a department and its alumni and current students weakens the department in more than one way. Without departmental ties with alumni, current students lose the potential to network with alumni who have taken their degree into the workforce. Also, while most students and faculty would agree there is room for improvement in higher 
education, what constitutes improvement -- and how to achieve it -- are difficult issues to address with limited information.

The focus of this research is on sociology as an academic major. However, when considering program improvement, it should be noted that sociology, like other social sciences, caters to a diverse audience. Sociology courses are not filled with majors who will continue on for graduate study in sociology. In reality, most sociology courses -- especially those which are not requirements for a major -- are filled with non-majors. Further, the research examined for this work and the experiences of survey respondents indicate that if sociology alumni do go on to receive a more advanced degree, it is more likely to be in a field outside sociology, such as counseling or education.

The rewards for those who study sociology are eloquently stated in the literature on the teaching of sociology and can make a discussion of "student satisfaction" seem somewhat disdainful. 
One eloquent description of these benefits is quoted by Smith (1990, p. 482):

The study of sociology liberates students from the provincialisms of time, place and circumstance and frees them from the constrictions of their natural culture.

Despite the claims of personal enrichment, there is scant research examining the effect of studying sociology on students. Do they feel they understand the world better? Are they liberated from the provincialisms of time, place and circumstance?

Meanwhile, sociology alumni are busy in the workforce and concerned with the perhaps less illustrious issues of rising housing costs and student loan payments. The conflict between the ideal of education for education's sake and the need of alumni to live in the "real world" is an organizing theme of this work.

It is important to acknowledge there are numerous tangible and intangible benefits for those who earn a college degree, regardless of their major or the quality of their educational experience. These benefits include increased cultural prestige, increased lifetime income, and higher job satisfaction. The 1995 Digest of Education Statistics reports the median annual income of year-round full-time workers 25 years old and over in 1993 (Table 374): 


\section{Figure 1}

Median Income by Education Level: 1993

Less than 9 th grade

Some high school (no diploma)

High school graduate

Some college, no degree

Associate degree

Bachelor's degree

Master's degree

Professional degree
$\$ 10,895$

$\$ 14,550$

$\$ 21,782$

$\$ 26,323$

$\$ 29,736$

$\$ 37,474$

$\$ 45,597$

$\$ 69,678$

Those with a college degree also show a greater gain in income over time.

Further, as the following chart using data from the 1995 Digest of Education

Statistics (Table 371) indicates, those with a bachelor's degree are less likely to be unemployed:

\section{Figure 2}

Unemployment rates of persons 25 years old and over by highest degree attained: 1993

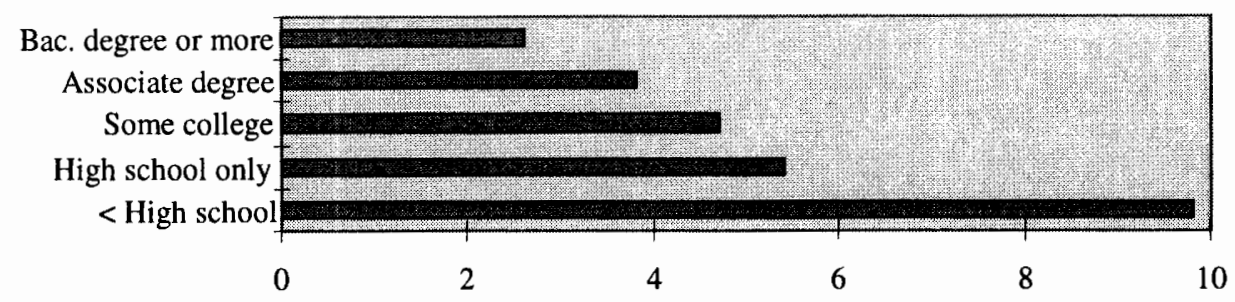

The inherent value of an undergraduate degree, however, does not preclude the exploration of ways to improve student experiences and outcomes. 
However, this work does not seek only to criticize -- without student feedback we do not know what our majors feel are the weaknesses or the strengths of the program.

\section{Statement of the Problem}

The main problem addressed herein is measuring degree program satisfaction in sociology at PSU and explaining its variation. Variation in program satisfaction is explained primarily by student characteristics. Areas explored include the respondents' level of job satisfaction, their demographic profile and their orientation toward how much applied training a degree program in sociology should offer. Program satisfaction is also examined from the perspective of current student or alumni status. The specific hypotheses are discussed in Chapter 2.

\section{Limitations}

This research is not a comprehensive evaluation of the Sociology department at Portland State University. Many factors influence the quality of a department, and student evaluation is only one component of an interrelated system of factors (how large a component is certainly up for debate). 
As with any research, the student/alumni perspective taken for this work impacts the issues raised -- excluding some areas and emphasizing others. Some argue, for instance, that a liberal arts degree should only be understood as an end in itself, a position that is precluded by the student-oriented perspective of this work.

The study did not include faculty input, nor did it compare sociology with other disciplines within the College of Liberal Arts and Sciences. Only PSU students and alumni were studied, and it is unknown how easily the results can be generalized to other universities. If conclusions about other universities can be made, similarities would more likely be with other urban universities that draw a similar student population.

\section{Significance}

The lack of research examining sociology from the student perspective makes this work exploratory. While there is literature on how sociologists see sociology and the teaching of sociology -- literature that is relevant and is presented herein -- there is little work exploring even the most basic topics such as the demographic profiles of sociology students. 
In the midst of academic cutbacks and restricted funding, it is important for sociology to examine ways to improve its standing both within and outside the university. The social sciences are not known for academic rigor or direct application in the workplace, especially when compared with the "hard sciences," such as biology or chemistry. However, sociology fares dismally, even when compared with other social sciences. For example, Cover (1995) alarmingly reports the findings of a study of academic deans who ranked sociology "the lowest of 10 disciplines both in teaching and in research quality" (p.227). William Rau (1992) warns: "At some universities, administrators have closed programs they perceive as academically weak to free up resources for stronger programs" (p.167).

What students do with their degree after graduation can be an important indicator of the general utility of sociological instruction (Watts and Ellis, 1989). By paying attention to the experiences of alumni, we invest in the future of the discipline. Measuring program quality only from a student perspective has inherent limitations. However, given the "considerable investment of time and energy that most students make in attending college, the student's perception of value should be given substantial weight" (Astin, p.304). 
Finally, in the words of a current sociology major:

I am so glad that there is a survey in the sociology department that could reflect our ideas and opinions. I enjoyed my school life at PSU, but I have some experiences that I would like to share with you... 


\section{CHAPTER II}

\section{REVIEW OF THE LITERATURE}

\section{Introduction}

This chapter begins with a demographic profile of sociology majors both nationally and at PSU. It continues with a discussion of sociology as a discipline and of research regarding the teaching of sociology. The model used in this work is presented along with the hypotheses tested. A discussion of the components of the model ends the chapter.

\section{Profile of Sociology Majors}

Whenever possible within this section, national, state-wide and PSU figures are included. This section starts with a look at the number of sociology and liberal arts majors in Oregon. Then different aspects of the student population are considered including the nontraditional nature of sociology majors, age, gender, student ability, and ideology.

The majority of students (both undergraduate and graduate) at Portland State University are liberal arts majors (the average from 1990-1995 is 64\%). 
During the 1993/94 academic year, there were 4,816 full-time equivalent students majoring in liberal arts. Of these, 263 (5.5\%), were sociology majors $^{1}$. In the state of Oregon, during the 1993/94 academic year, 338 sociology bachelors degrees were awarded, along with 8 masters degrees and $8 \mathrm{PhDs}$.

Since 1982 women have earned more college degrees than men (Jacobs, $1995)^{2}$. However, women tend to be concentrated in certain fields, including the social sciences, and underrepresented in other fields, especially engineering and the "hard" sciences. Sociology is no exception to this pattern.

Significantly more women than men major in sociology, both nationwide and at PSU. During the $1993 / 94$ academic year, $48 \%$ of all students at PSU were female while $75 \%$ of sociology undergraduate students at PSU were female. Nationally, data from the National Center for Educational Statistics (1995) shows that $68 \%$ of bachelor degrees in sociology are awarded to females.

\footnotetext{
${ }^{1}$ These numbers come from the University's Fact Book and are based on declared major.

${ }^{2}$ Women continue to be underrepresented in engineering and the sciences and at the higher degree levels for all disciplines (Jacobs, 1990).
} 
College students in general tend to be older than they were 20 years ago and are more likely to have attended a junior or community college (McGee, p.16). Department of Education statistics from the 1995 Education Statistics Digest, show that the number of older students has been growing more rapidly than the number of younger students. Between 1980 and 1990, for example, the enrollment of students under age 25 increased $3 \%$ while the enrollment of persons 25 and over rose $34 \%$. Sociology also "attracts a slightly higher proportion of older students," (Wagenaar, p. 355) a fact that is reflected at PSU. The External Review Report of Fall 1991 stated the average age of sociology majors at PSU to be 27.5 while the average age of undergraduates at PSU in the same year was 26.6.

According to the Report to the University by the PSU Committee on Undergraduate Student Retention (1993), PSU attracts many students who “...are non-traditional. They are not recent high school graduates...Many come to the University with careers already established. Most of our students say they must work, at least part-time." (p.13).

Nationally, sociology tends to have more part-time students than other disciplines as well as higher percentages of minority students. Perhaps because of their part-time status, sociology majors tend to be less integrated 
into their department than other majors. Sociology majors, for example, are less likely to know someone else in their major than are students in other disciplines (Wagenaar, 1993). PSU has characteristics that further inhibit sociology majors' integration. The 1993 Report to the University by the PSU Committee on Undergraduate Student Retention reported that student interviews conducted at PSU revealed that the "large and sometimes impersonal nature of PSU" (p.12) is troubling to some students. Also, "several students complained that it was difficult to meet individuals who were similar to themselves" (p.12).

Wagenaar reports that nationwide "only 35 percent of sociology students report having at least one parent with a college degree, compared with 76 percent for students in other disciplines" (p.355) and suggests this may indicate sociology majors have a lower socio-economic status than other majors. The education level of the parents of PSU sociology students was found to be somewhat higher - this data is discussed in Chapter 4 .

Nearly half of all undergraduates nationwide receive some form of financial aid. This number decreases with age -- i.e., those over 30 are less likely to receive aid than those under 23 . Full-time students are more likely to receive aid (57.9\%) than part-time students $(32.9 \%)$. The average amount of 
financial aid for the academic year 1992-1993 nationwide (not including grants) was $\$ 5,543$. The financial aid office at Portland State University was unable to provide comparative information for PSU.

Some researchers argue that the caliber of sociology students is lower in sociology than in other disciplines. Standardized test scores such as SAT and ACT scores are lower for sociology majors than other majors or university averages. As measured by GRE scores, sociology majors are at, or near, the bottom, depending on the year and the source. Becker and Rau (1992) state that sociology majors rank twenty-fifth out of twenty-five on the GRE verbal section and twenty-second out of twenty-five on the quantitative section. Test score information by major was not available for Portland State University.

William Rau (1992), while discussing the lower scores of sociology majors, notes that there is a demoralizing increase in students who "lack preparation, motivation, or interest in the study of sociology" (p.166). The lower level of student ability makes it more difficult to "teach well in sociology than in most other fields because it is more difficult to teach average or below average students than bright students" (p. 166). 
Turner (1990), Huber (1995) and others discuss the politicized and idealistic nature of students who are drawn to sociology. Wagenaar (1993) reports that the results of his study of sociology graduates suggests "students select sociology because it may help them address personally significant issues or that the discipline attracts more socially aware [if not academically capable] students" (p.356). It has also been suggested that women and minorities have been attracted to sociology because it directly addresses issues affecting their lives (Wagenaar 1992).

Turner argues that during its rise in the late 1960s, "[s]ociology became the academic program that absorbed many of the most politically committed students of the era" (p. 138). Sociology at this time began to be seen by students as a liberating force, a tool in the fight against social injustice. As Peter Berger puts it in his essay Sociology and Freedom (1971), “[p]lacid purveyors of Parsonian theory are suddenly confronted with the demands to be "relevant"...collectors and producers of multiple correlations with impeccable margins of error, suddenly hear themselves denounced as academic hirelings of the military-industrial complex" (p.1).

Devlin and Peterson (1994) argue, however, that during the 1970s and 1980s, this trend towards idealism began to shift as "both society and students 
directed their perspectives toward individual achievement and reward" (p.154) when considering college major and careers. This was not borne out by the research performed herein (and discussed in Chapter 4) - the respondents were found to be altruistic, especially in their motivation for choosing sociology as a major.

\section{Sociology as a Discipline}

Sociology as an academic discipline began to be organized at the end of the 19th century (Baker and Rau, p.171). Many of the first sociology students came from economics or the clergy, and were drawn to sociology as the "science of society." In the 1920s the "preachers and reformers were thrown out and academic warfare broke out between the positivistic methodologists and the antipostivisitic theorists" (Baker and Rau, p.172).

The early 1960s ushered in a period of restructuring of the educational system in the United States. This restructuring resulted from, among other things, the Cold War between the United States and the Soviet Union. The launching of the satellite Sputnik in 1957, for example, was a call to arms for many reformers who felt the United States was in danger of falling behind 
and eventually succumbing to communism. During this time period, the number of universities grew significantly as did funding for social research.

Beginning in the early 1960 s there was a significant increase in student demand for sociology as well as an increase in federal funding for sociology. During this time period, degrees in the social sciences increased, peaking at $20 \%$ of all bachelor degrees awarded in 1965 (Turner and Turner, 1990).

Figure 3 below, compiled from Turner and Turner's data, shows the changes in the number of undergraduate degrees awarded since 1949.

Figure 3

Number of Sociology Undegraduate Degrees Awarded

Nationally from 1949 to 1992

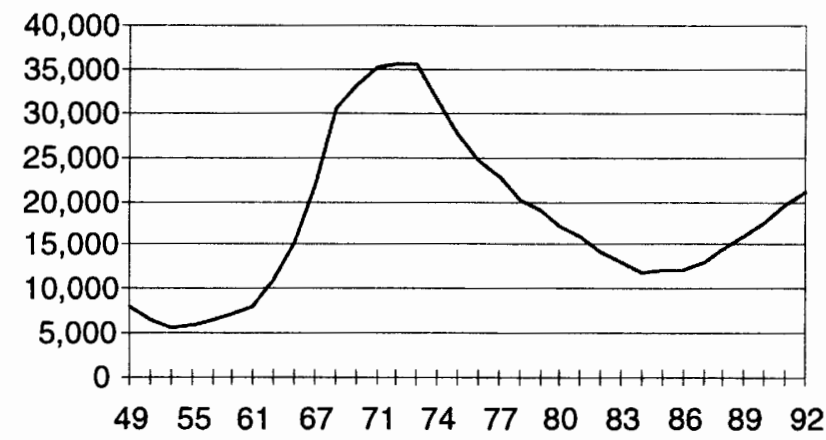

The decline in the 1970s (and subsequent rise) in sociology degrees awarded has paralleled the degrees awarded to all social science majors ${ }^{3,4}$. In order to

\footnotetext{
${ }^{3}$ This figure includes sociology majors
} 
compare the changes in sociology degrees with the changes in the total number of social science degrees, the yearly figures were standardized in the following way:

number of degrees awarded in sociology for specific year mean number of sociology degrees awarded from 1971-1993

number of degrees awarded in social science for specific year mean number of social science degrees awarded from 1971-1993

Through this process, a ratio was created which allowed the comparison between sociology and the social sciences seen in Figure 4 .

Figure 4

Trend of Undergraduate Degrees in Sociology Compared with Degrees Awarded in the Social

Sciences: 1971-1993

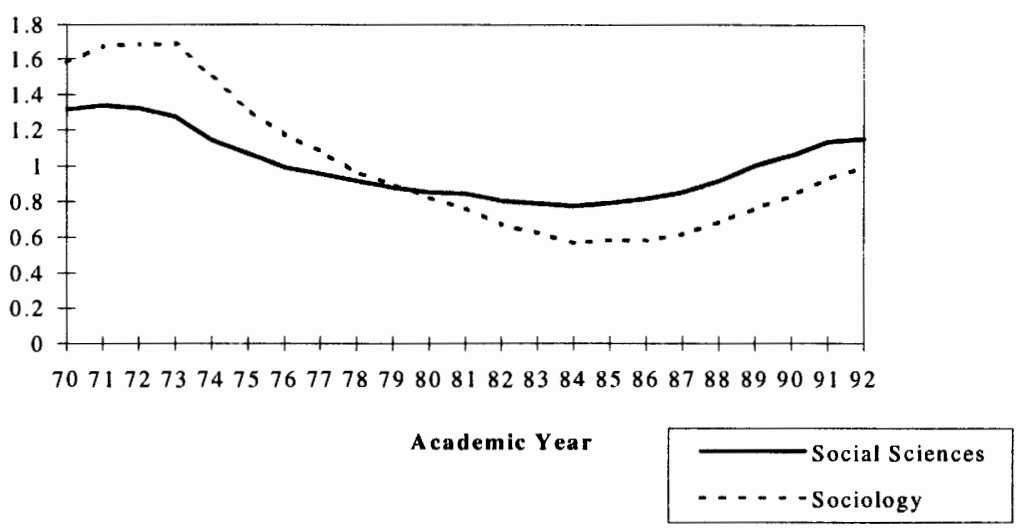

${ }^{4}$ source: 1995 Digest of Education Statistics 
The federal funding for sociology peaked in the early seventies, and the number of PhDs and master's degrees peaked in 1977 and 1974, respectively. The number of social science and sociology undergraduates began increasing in the late 1980 s, a trend that continues today and which remains largely unexamined in the literature.

The dramatic increases in funding and student demand during the early sixties led to the increase in the number and size of sociology departments. While the number of students in sociology was rising in the 1960 s, so was the professionalization of sociology (Turner and Turner, 1990), as evidenced by (among other things) the growing membership in the American Sociological Association.

Nearly all two and four year colleges and universities underwent some type of curriculum change during the 1970 s and 1980 s as educational reforms were widely adopted nationwide. Much of the debate that led to these reforms centered around improving the general education level of graduates by increasing the number of courses outside of one's academic discipline required for graduation. These reforms had an impact on sociology by dramatically increasing the number of non-majors in sociology classes. This 
increase eventually led to the minority status of sociology majors in most sociology courses.

The 1993 General Education Working Group Report and Recommendations reports that "Portland State University was not untouched by the wave of curricular reform efforts in the 1980s" (p.12). The issues raised during this period at PSU included the purpose, goals, and objectives of the general education requirement. There ensued a struggle over "which courses would count toward meeting the distribution requirements and who would decide" (p.14).

\section{Sociologists on Sociology}

While there is little research regarding the outcomes and experiences of sociology majors, there is much discourse in the literature of the supposed sad state of sociology itself (see, for example, Wright 1990; Lynch 1993; Becker \& Rau 1992; Huber 1995). This internal conflict, discussed below, impacts sociology majors both inside the classroom (e.g., what subjects are taught and by whom) and outside the classroom (e.g., the level of community within the department). 
The 1993 book, A Critique of Contemporary American Sociology, expresses the common sentiment that sociology is floundering and needs major work. In his recent presidential address to the Pacific Sociological Association, Jonathan Turner stated that “...it would not be a bad thing for sociology to simply disintegrate into specialty associations or to merge into other interdisciplinary programs" (quoted in Hobbs, p. 472).

Ironically, there is even criticism for being distracted by criticism: Freeman and Rossi (1984), for example, argue that

because sociology has turned inward and has focused on its own disciplinary problems, we have been faulted by many in influential positions for the lack of relevance of our work to the solutions of contemporary social and political problems (p.571).

Every discipline, of course, engages in some form of self-examination. However, since sociology is charged with understanding society, and sociology is part of society, it is perhaps not unexpected to find a certain amount of internal dissension.

Sociology has been challenged both internally and externally as academically weak, a fact not lost on its majors who take the degree into the workforce. 
For example, Tom Hobbs (1993) points out that sociology has not only "contend[ed] with internal dissension, but also with serious assaults on its very right to exist as a bona fide discipline" (p. 471). A common theme in the literature critical of sociology undergraduate programs is a perceived lack of disciplinary cohesion and its impact on the quality of undergraduate training. This issue is discussed below.

\section{Professional Fragmentation}

According to some researchers, fragmentation within the discipline of sociology stems from a historical desire on the part of the professional structure to accommodate all specialties, no matter how disparate. For example, when the American Sociological Society was reorganized into the American Sociological Association there was an opportunity for the consolidation of the discipline into a cohesive structure, something which some argue was lacking up to that point. However, Turner and Turner (1990) argue that it was not to be; that in fact, the result was "an almost complete inability to consolidate symbolic resources around either a sense of common professional community...or a common corpus and storehouse of knowledge" (p. 139). 
An effective response to the subsequent decline in funding in the late 1960s was hampered by this lack of cohesion and "encouraged even further differentiation...partly as a result of trying to sustain membership in ASA by giving anybody and everybody a niche in sociology" (Turner and Turner, p.140). Also, the growth of regional associations and journals further weakened the ASA and made it less powerful.

Becker and Rau (1992) called the micro-specialization "hopeless fragmentation" (p.72) and argue that it is at least partially responsible for the low quality of sociology undergraduate training. For example, if professors teach what they are interested in and if their interests are fragmented, so are the departmental offerings.

Conklin and Robinson (1985) argue that the decline in the number of sociology majors may be because as professors try to cover the myriad of topics addressed by sociologists they "no longer offer an intellectually interesting course of study" (p.67). Others argue that teachers barter to teach their own highly specialized courses in exchange for teaching classes they are forced to take on due to personnel shortages or high demand for introductory classes. 
Guppy and Arai (1994) echo this argument in their work comparing the curriculum in sociology in the United States and Canada. They state that "fractures or lesions imply dissensus and disarray..." (p. 218) and keep sociologists isolated from each other within departments. Weak communal norms are the outcome of a lack of a common language, a common area of focus, and weak departmental community (Huber, 1995). Strengthening these communal norms might improve classroom instruction and professional performance.

\section{The Teaching of Sociology}

The vast majority of contact hours an undergraduate spends with their department is during class time. The quality of teaching has a direct impact on the value of the degree and on the overall quality of the degree program.

There is much formal and informal discussion of the quality of teaching in sociology (including an entire journal devoted to the topic) and how to improve it. Sociology, of course, is not the only discipline that has received criticism for the quality of classroom instruction. Rau and Baker (1992) believe that college teaching in general has had limited progress and quip: 
"The last really notable advance in college teaching was the invention of the printing press" (p. 161).

Guppy and Arai (1994), in their analysis of undergraduate training, found "great variability...in individual institutions as to what constitutes adequate training in sociology" (p.220). And yet, the quality of the classroom instruction is a fundamental component of the undergraduate experience. For example, Bruton and Crull (1985) found that the most important feature predicting student's learning in introductory courses was the instructor. At the same time, PhD programs in sociology (as well as other social sciences), place limited (if any) emphasis on training candidates to teach, even though teaching is a large component of a professor's job. To further compound the problem, professors are most often rewarded professionally for accomplishments outside of the classroom.

Rau and Baker (1989) offer two of the strongest voices for the improvement of undergraduate instruction and believe that universities have become "increasingly bureaucratized and increasingly professionalized at the same time. One process feeds the other; they work in tandem to create the modern university, and neither is a friend of undergraduate education" (p.164). Using a systems approach to the issue, they have created a model that tries to 
explain the lack of quality instruction. As can be seen in the following component of that model, they have examined the professor's role along its two main components: teaching and research.

\section{RESEARCH}

\begin{tabular}{cc|cc|}
\multicolumn{1}{c}{ TEACHING } & \multicolumn{1}{c}{ LOW } & HIGH \\
\cline { 3 - 4 } & LOW & Lifers & Scholars \\
\cline { 3 - 4 } & HIGH & Master Teachers & Virtuosi \\
\cline { 5 - 5 } & &
\end{tabular}

They argue that the current university system does not provide a niche for Master Teachers or credit for universities that focus on teaching: "teaching accomplishments are not calculable in the coin of the realm" (p.167). They argue strenuously for "creating a system of accountability for classroom teaching" (p.173).

In discussing the role conflict for professors, it is noted by Rau and Baker (1994) that "Other things being equal, departments with prominent faculty members or success in attracting grants are most likely to avoid the axe" and yet, at the same time "[f]aculty may be rewarded and promoted for scholarly attainments, but they are paid to teach" (p.169). In a later essay published in 
Teaching Sociology (1992), William Rau notes that "[p]owerful institutional forces conspire to limit teaching to a marginal role in academe" (p.165).

At least until the 1988/89 academic year, there was a tremendous decline in the number of undergraduate students in sociology. Sociology had 35,491 graduates in the $1973 / 74$ academic year (the peak) as opposed to 14,329 graduates in the 1988/89 academic year. Sociology had a higher percentage loss than any other discipline in the sciences or humanities (Cover, 1995).

Most sociology departments are expected to offer quality training to a large quantity of students with a small quantity of instructors. Faced with large classes staffed by overworked instructors, undergraduate students may find it difficult to identify with their major and/or gain the types of experiences they would like to help them in their future job searches. Departments, on the other hand, must struggle with the reality that high enrollment helps to stave off the possibility of funding reduction (or even departmental dissolution) while at the same time, "institutions' dependence on enrollments to remain solvent tends to erode their autonomy and academic quality" (Huber, 1995, p.197). 
While the majority of sociology courses at PSU and other universities are filled to capacity (due primarily to large numbers of non-majors meeting university requirements [Roberts, p. 207]), departmental resources have remained static or declined (Brunton \& Crull, 1984). The 1994 University Fact Book for PSU shows that sociology has the highest student/faculty in the entire university: 46:1. In fact, no other discipline is remotely close except for Women's Studies (45:1) -- the next closest is Public Health Education with 35:1) -- and both of these departments have only one fulltime faculty member.

\section{The Model}

The information in the proceeding sections is intended to provide the background for the study of degree program satisfaction. Having considered the history of sociology as a major, discussed some of the problems sociologists have asserted are currently present in the discipline, and examined the teaching of sociology, this section presents and discusses the components of the model used to frame the issue of degree program satisfaction. This section begins with a discussion of the outcomes of 
sociology alumni and the main independent variable of the model, degree program satisfaction.

\section{Alumni Outcomes and Degree Program Satisfaction}

While social science alumni "often value their degree most for contributing to personal growth and providing a liberal arts background, we may reasonably enquire about the extent to which [a degree in sociology] engenders degree and job satisfaction" (Kressel, 1991, p.222). Sociology majors are less likely than other majors to find jobs directly related to their major and according to Kressel (1991) "many would be apt to choose differently if they could select their major again" (p.222). One study showed that $30 \%$ percent of sociology graduates felt their work was strongly related to their major as opposed to $50 \%$ of all employed college graduates (Wagenaar 1993).

Of course, there are relatively few jobs that are directly related to sociology when compared with other disciplines. However, seniors in sociology, when compared with other social science majors, are more likely to predict they will be able to find major-related employment after graduation, a prediction 
not borne out in reality. This discrepancy "between expectations and reality may cause some anxieties for [sociology] students" (Wagenaar, p.356).

Some researchers (e.g., Sharkey; 1990) believe that a sociology major should be organized around student outcomes and there should be discussion within departments as to "what their students ought to be able to do as a result of going through their general curriculum, their major, or specific courses" (Sharkey, 1990, p. 472). McGovern \& Hawkes (1987) encourage an examination of alumni outcomes to protect the future of universities that depend upon the enrollment of "students who want to guarantee the ability to pay back increasing loan amounts" (p.52). Also, improving the applied side of sociology may help attract more qualified majors as well as "improve its standing both within and outside academia" (Freeman and Rossi, p.572).

The majority of sociology majors move from the university directly into the workforce (or remain in the workforce, as the case may be) rather than continuing their education in graduate school. In recent years there has been increasing concern on behalf of both faculty and students regarding the ability of these graduates to obtain suitable employment (Watts and Ellis). McGovern and Hawkes (1987) argue that research should examine what 
types of tasks alumni perform on the job and look at how those skills are developed (or not) during their undergraduate training.

Degree program satisfaction is the dependent variable for this work. It is conceived to be the level of positive feelings one has towards the department and towards their degree. It is measured by a series of statements presented to the respondents in Part I (question 3) of both surveys (see Appendix A). For example, respondents were asked if they felt their degree was a good use of their time and money. Agreeing with negative statements ("My sociology major consisted of a collection of more or less unrelated courses") lowered the satisfaction score.

The following model was constructed as a way of explaining degree program satisfaction. Essentially, degree program satisfaction is understood to be a result of the influence and interaction of the variables in the model. The specific hypotheses tested in this research are presented at the end of this chapter. 


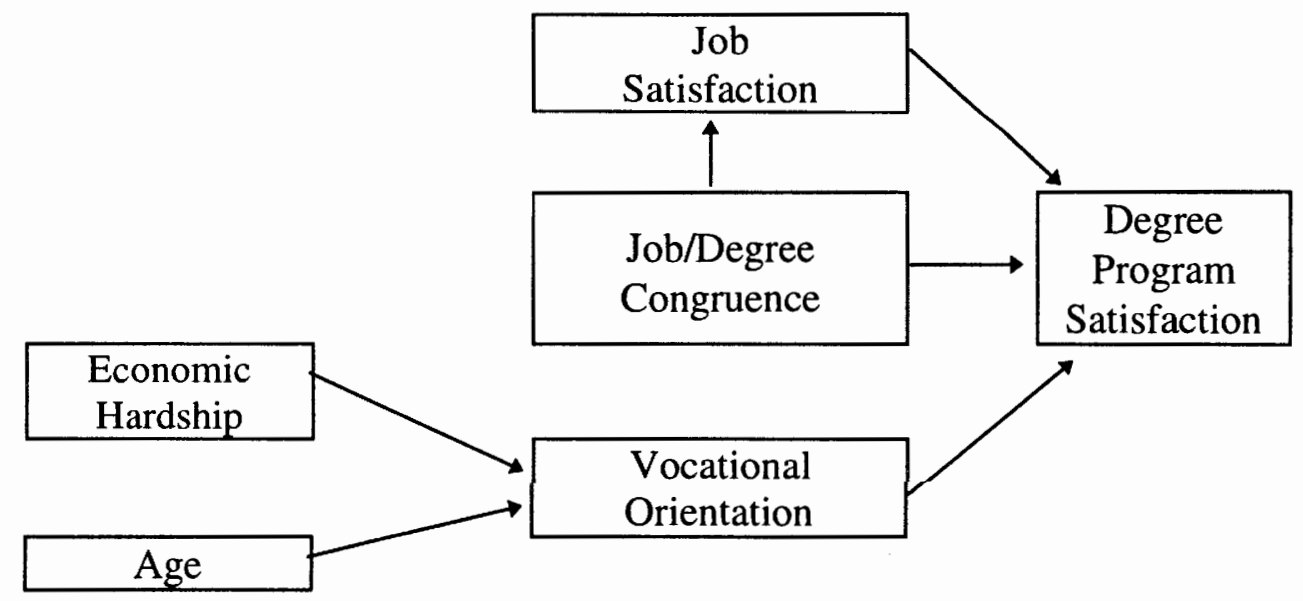

Hardship

The level of economic hardship a student incurs to attend college.

Age: $\quad$ The age of the respondent.

Job Satisfaction: This concept is measured by attitudinal questions such as "Other than a paycheck, my job has little meaning to me."

\section{Vocational/Liberal}

Arts Orientation: Is the student more interested in gaining a broad, liberal arts education or is their focus on gaining skills and experiences that will assist them with employment?

\section{Job/Degree}

Congruence:

Does the student feel their job is related to their degree or vice versa?

The level of economic hardship incurred by students and their age are the starting point for the model. These variables are not hypothesized to be related to each other and their variation is caused by factors unexplained by 
the model. These variables are hypothesized to be an influence on the respondent's vocational/liberal arts orientation.

Specifically, it is hypothesized that the harder it is financially for a student to attend college, the higher their expectations will be for the degree program in terms of vocational or applied training. Also, it is hypothesized that the more useful one feels their degree is to their job (congruence) the more satisfied they will be with their job (which in turn will increase their satisfaction with the degree program).

The circumstances that are hypothesized to be inversely correlated with degree program satisfaction are 1) a high vocational orientation; 2) low congruence between the degree and current job; and 3) a low satisfaction level with their current position.

\section{Job Satisfaction and Job/Degree Congruence}

Two of the factors hypothesized to influence degree program satisfaction are job satisfaction and the level of job/degree congruence - e.g., does the respondent use their degree in their work? Research has shown that job satisfaction has a positive impact on the rating of a degree program by 
alumni and student's approval of their undergraduate degree programs is related to the "extent that the educational process or degree is perceived to open the door to higher statuses" (Kressel, p. 302).

\section{Vocational/Liberal Arts Orientation}

The question What is the purpose of an undergraduate degree in sociology? is raised by this work. The answer to this question is complex and depends on, among other things, who is being asked. To seek a better understanding of this issue and to better understand student degree program satisfaction, this question is addressed in the following way. A continuum is drawn below with a strictly applied orientation at one end and a pure liberal arts orientation at the other. The assumption is that alumni and current students come into the program with this orientation intact, based upon their prior experiences and background.

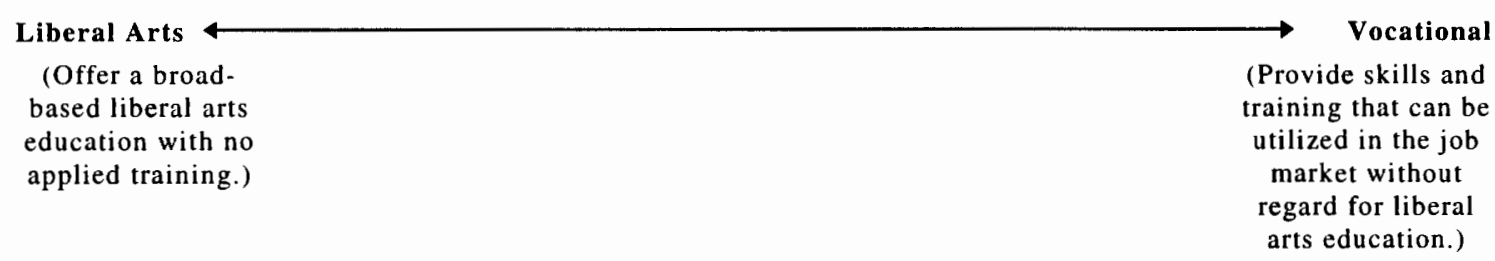


Within academia, it is not uncommon to find resistance to the idea of a liberal arts degree being anything other than an end in itself, and that anything else compromises the integrity of the degree. Some faculty believe that "either we offer a quality educational program with a rigorous core curriculum or we pander to students' needs and become a vocational training program" (McGovern and Hawkes, p.179).

When entering Portland State University students were asked ${ }^{5}$ : How important is each of the following to you as a reason for studying at PSU at this time?, $59 \%$ of transfer students and $64 \%$ of high school students listed "Preparing for a career" as Very Important while $21 \%$ of transfer students and $24 \%$ of high school students listed "Gaining a broad basèd general education" as Very Important. The report further stated "It is no secret that most students enter higher education with preparation for a career as their primary goal" (p.22). And yet, students also clearly want a broad liberal arts education. Again, from the General Education Group's report review of the literature on why students attend college:

\footnotetext{
${ }^{5}$ Source: General Education Working Group Report and Recommendations, Portland State University, October 1993
} 
The implication is that students enter college not just to receive career training but also to a significant degree to gain a well rounded education or a good general education.

Freeman and Rossi (1984) argue that while academic opportunities for sociology graduates have been diminishing due to funding and other issues, sociologists have not paid attention to applied training, "especially when compared with our kindred disciplines of economics and psychology" (Freeman and Rossi, p.571). Methodology courses may in fact be the most useful in terms of providing alumni with marketable job skills (a finding reflected in this research) but are often treated as a "special domain reserved for graduate students, taught only by the departmental methodology specialist, and in one or two designated methodology courses" (Schwartz, p.491).

Not all evidence suggests a gap between students and departments regarding the purpose of a degree. McGovern and Hawks (1987), for example, did a survey in a psychology department with questions similar to the one asked here, however, they included the faculty as well as current students (not alumni). While they found differences between students and professors in the rankings of what a psychology major should learn, professors and 
students appear to feel there is a need to have both applied and liberal arts components in a degree program. The table below presents the top four answers for each group and indicates that the two groups are not too far apart:

\section{Students}

1. Scientific principles of behavior

2. Receive career assistance to use BA/BS degree

3. Read and evaluate psychological research

4. Developmental patterns of behavior

\section{Professors}

1. Help other people

2. Get practical experience

3. Receive career assistance to use BA/BS degree

4. Best preparation for graduate school

Finally, the orientation to this issue utilized for this work is aptly summed up by McGovern \& Hawks (1987): "The question always has been how an institution mixed the academic with the vocational, not whether it did so" (p. 179).

\section{Hypotheses}

The following are the main hypotheses tested for this work. These hypotheses were informed by the underlying assumption of this work that there is a conflict between the ideal of education for education's sake and the 
demands of the "real world." They are intended to quantify the relationships in the model which were presented earlier in this chapter.

1. Current students will be more satisfied with the degree program than alumni students.

2. The older a respondent is, the more likely they are to have a vocational orientation.

3. The more hardship one endures to obtain their education, the more likely one is to have a vocational orientation.

4. The more satisfied a respondent is with their job, the more highly they will rate their degree program satisfaction.

5. The stronger a respondent's orientation to liberal arts, the more satisfied they will be with their degree program.

6. The more useful the respondents feel their job is in their current employment situation, the more highly they will rate their degree program satisfaction. 
7. The more useful the respondents feel their degree is to their current job (congruence), the more satisfied they will be with their jobs. 


\section{CHAPTER III}

\section{PROCEDURES AND METHOdOLOGY}

\section{Introduction}

This chapter discusses the design of the research, the population studied, the instrument used and statistical tests and procedures performed on the data. The study utilized a survey instrument mailed to all recipients of an undergraduate degree in sociology (alumni) and all students presently majoring in sociology (current students). These names were generated using BANNER, the university-wide student data base. Difficulties with generating a comprehensive list of current students are discussed below. Statistical analysis was done using a popular software package, SPSS for Windows as well as a word processor for organizing qualitative data.

\section{Population}

The population for this study consisted of all students who had received an undergraduate degree in sociology from PSU since the inception of the department and all students currently majoring in sociology. 
A comprehensive list of sociology alumni was obtained from the BANNER system and the alumni office. In order to verify the names and addresses from the BANNER system, randomly selected names were pulled from each of the lists and contacted by phone. Not surprisingly, this method showed the alumni office list to be substantially better than BANNER for alumni information, and this list was used to generate the mailing labels for the alumni surveys. However, the alumni list is biased in favor of those who have kept in contact with the alumni office and/or who have remained geographically stable. Over one thousand surveys were mailed to alumni students and 332 viable surveys were returned, generating a response rate of 31.5 percent.

No surveys were returned to the department as undeliverable. There was no follow-up performed. It was felt that the time and financial burden of tracking responses and mailing a second wave of surveys were prohibitively high when compared with the anticipated benefit. The response rate achieved with one mailing was similar to those studies where more than one wave was mailed out.

For current students, a list of those declaring sociology as their major was generated using BANNER. Every tenth person was contacted by phone to 
ascertain the validity of the list. The majority of the respondents contacted were indeed sociology majors. The final current survey list consisted of 265 names and close to 100 surveys were returned. The specific return rate is discussed below.

This method for generating a list of all current sociology majors was undoubtedly flawed. Students are not required by the university to state their intended major, or to change their officially intended major should they change their minds. Some of the returned surveys were from those who were erroneously listed as sociology majors. Unfortunately, as the survey was mailed in August, it was not possible to go into large numbers of sociology classes and attempt to further untangle the problem of how to find current sociology majors.

It is unknown if there is a bias in the type of student that has their major registered with the university. Eighty-four viable surveys were entered for analysis with a response rate of 31.7 percent, virtually identical to that of alumni. 


\section{Data Collection}

Data collection was done via a four page survey mailed to respondents (see Appendix A). For this project, a survey best suited the needs of the researchers, namely, to gather limited information from a large number of people.

During the instrument creation process, professors who had performed similar research were contacted for samples of their surveys. Four relevant surveys were obtained in this manner. These surveys were helpful in the structuring of the final survey as well as providing a reassuring reality check; none of the surveys was close to the ideal type presented in methodology classes. All were flawed, and most had typos, and all had been used to generate data upon which published articles were based.

The surveys for current students and alumni were similar. Verb tense was changed to reflect the student's status in relationship to PSU. Current students were asked more specific questions about how they came to major in sociology, as it was assumed their recall would be better than alumni.

Similarly, current students were asked why they decided to attend college, as well as why they majored in sociology. All respondents were asked basic 
demographic questions including the education level of their parents, their personal income, and how they were paying for college. Also, all respondents were asked to suggest improvements they felt could be made to the undergraduate program in sociology at PSU.

Both alumni and current students were presented with a series of Likert questions aimed at understanding their attitudes toward sociology in general and at Portland State in particular. Alumni were asked to list any sociology/non-sociology classes or professors that had been beneficial to them either personally or professionally since graduation. Alumni were also asked to identify the tasks and activities they perform at their current job as well as Likert items regarding their satisfaction with their current job and the usefulness of their degree in that position. In addition, they were asked about their present level of education and their plans for further education.

Both alumni and current students were presented with a table of skills and experiences (e.g., computer skills, studying topics such as stratification, inequality and social class) and they were asked to place a level of importance upon each. Alumni were asked to do this exercise based upon their experiences since graduation and current students were asked to consider an undergraduate program that would best suit their needs. After 
indicating a level of importance for each skill/experience, the respondents were requested to rank which ones were the top three in terms of importance. This section was specifically designed to have an equal number of applied/vocational items (e.g., Department coordinated internships) and liberal arts items (e.g., the development of critical thinking skills).

Once the surveys were compiled, a pilot study was done. Surveys were distributed $(n=25)$ in different sociology classes, and were mailed to sociology alumni known to the researchers in order to test respondent's understanding and to seek ways to improve the instrument. Sample surveys were also given to members of the committee as well as the chair of the department. As a result of this process, the survey was modified and a finalized version (see Appendix A) was mailed to the pool of potential respondents.

The surveys were mailed with a postage-paid return envelope. A cover letter accompanied each survey (see Appendix A), identifying the researchers as graduate students and soliciting the respondents' help in conducting thesis research on the undergraduate degree program in sociology at PSU. The 
differences between the current student and alumni cover letter were minimal.

The decision to identify ourselves as students was thought-out and deliberate, as we felt students and alumni would be more likely to 1) help out "fellow students", thereby increasing the response rate; and 2) fill out the survey more candidly, knowing the results were not going directly to a specific professor or to "the department."

As the surveys were returned they were edge-coded and numerical data was entered into the computer using Microsoft Excel, version 5.0. Once all the data was entered, the numbers were checked by re-entering every tenth survey. The error rate was found to be negligible, and the data was considered reliably recorded. The ASCII file containing the data was then imported into SPSS for Windows, version 6.1, and prepared for analysis. All textual data was entered into the computer using Microsoft Word, version 6.0 .

\section{Statistical Treatment}

Data was analyzed using SPSS for Windows. The data was initially examined using a complete set of frequency tables. This allowed for visual 
inspection of the different variables and allowed a further opportunity for error-checking. After the frequency tables were generated and checked, the data was analyzed using a variety of methods including cross tabulations, factor analysis, linear regression and means comparisons. A variety of scales were created based upon factor analysis to simplify the data for further analysis. Where appropriate and possible, qualitative data was quantified and new variables were created. Other qualitative data was analyzed for themes and/or was used anecdotally.

Hypothetically, the intended population of this study (all alumni and all current students) was accessed and the data collected need not be treated as a sample. However, concerns regarding the viability of the sampling frame for the current students warranted a more conservative approach and the data set was treated as a sample and subjected to appropriate tests of significance. 


\section{ChAPTER IV.}

\section{PRESENTATION OF FINDINGS}

\section{Introduction}

This chapter contains a summary of the data collected from the surveys (see Appendix A). As noted earlier, the response rate for alumni and current students was similar -- around $31 \%$. Of the 416 surveys analyzed, $79.8 \%$ $(n=332)$ were alumni and $20.2 \%(n=84)$ were current students. Unless otherwise noted, alumni and current student data is examined separately.

\section{Profile of Respondents}

The first characteristic examined was gender. The current students contained a higher percentage of females (77\%) than the alumni (69\%). However, the difference in gender between the groups was not statistically significant at the .05 level. Initially, the difference between alumni and current students was thought to be due to increases in the number of women attending college over time. However, this explanation proved inadequate. Overall, there is no statistically significant relationship between age and gender (mean age for women is 41.2 , for men 41.8 ). There is, however, a statistically significant 
$(p>.05)$ tendency towards a higher proportion of males for those graduating in or before 1979 (61\% female) when compared to those graduating in 1980 or later $(73 \%$ female $)$.

According to the 1994 University Fact Book, $48 \%$ of all PSU students are male, however sociology in general has a higher ratio of females to males. Nationwide in 1989 , for example, $73 \%$ of sociology majors were female, while the percentage of females in other social sciences was $68 \%$. On the other hand non-social science majors were $46 \%$ female. Combining the current students with the alumni, the respondents were $69 \%$ female. This number was consistent with the ratio found in the Oregon Higher Education System -- $66 \%$ of the bachelors degrees in sociology awarded in the state of Oregon in the 1993/4 academic year were awarded to women.

As would be expected, alumni were (on average) older than current students: the mean age was 41 for alumni and 30 for current students. The mean age for all respondents was 39 years. The average age for current students is higher than the university-wide average for undergraduates of 26 . This finding is consistent with other research on sociology majors. Wagenaar (1993), for example, discusses a report from the Association of American 
Colleges which found sociology majors to be (again, on average) 2 years older than majors in other social sciences.

The following table summarizes the findings on gender and age:

\begin{tabular}{|c|c|c|c|c|}
\hline & $\begin{array}{c}\text { All Survey } \\
\text { Respondents }\end{array}$ & Alumni Only & $\begin{array}{c}\text { Current } \\
\text { Students Only }\end{array}$ & $\begin{array}{c}\text { PSU Students } \\
\text { (all majors) }\end{array}$ \\
\hline $\begin{array}{l}\text { Percentage } \\
\text { Female }\end{array}$ & $69 \%$ & $67 \%$ & $77 \%$ & $52 \%$ \\
\hline Average Age & 39.1 & 41.4 & 30.5 & 26.6 \\
\hline
\end{tabular}

Many students attending PSU are first generation college students. "Fiftytwo percent of the 1992 entering students reported that neither of their parents had completed a two or four year degree program" (General Education Working Group Report, p.28). Research of sociology alumni shows that $35 \%$ of sociology majors have at least one parent with a college degree $-13 \%$ fewer than the PSU average. University data on parental education level was not broken down by department so a comparison is not possible.

All respondents were questioned about the education levels of both their mother and their father. The fathers of current students had the highest average level of education -- $61.3 \%$ had at least some college (see Figure 5). 
Alumni had the lowest overall level of college educated mothers, $54.3 \%$. A possible explanation for the lower educational level of alumni mothers is the overall higher age of alumni. There is, for example, a small $(r=.21)$ inverse relationship between the age of the respondent and education level of the mothers. This finding is consistent with the historical patterns of women's college attainment - women are currently more educated than in earlier generations.

Figure 5

Education Level of Mother and Father by Alumni/Current Status

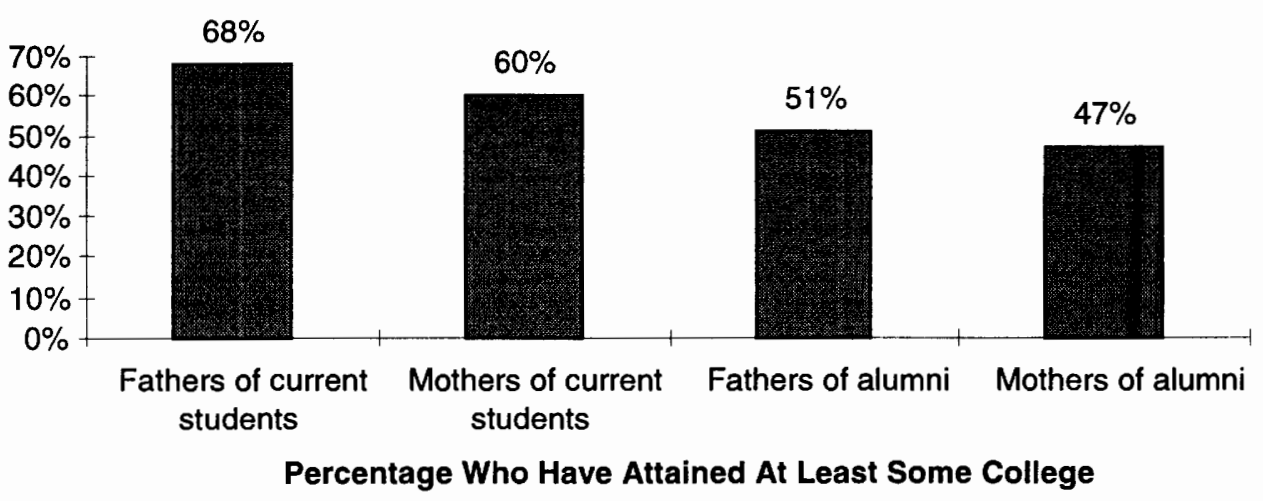

When comparing those whose parents have at least a 4 year degree (as opposed to having at least some college) the pattern changes. First of all, the percentage of respondents with at least one parent with a college degree was remarkably similar between alumni (47.9\%) and current students (48.2\%). 
Also, the mothers of current students are less likely to have at least a 4 year degree than alumni ( $23 \%$ vs. $32 \%)$ while their fathers are more likely to have at least a bachelor's ( $42 \%$ to $34 \%$ ). It is unknown why these number are higher than those found by Wagenaar (he found that $35 \%$ of sociology majors have at least one parent with a degree).

The vast majority of alumni are employed. Over $70 \%$ of the alumni respondents were employed full-time; $13 \%$ were employed part-time; and only 6 respondents $(2 \%)$ indicated they were unemployed and looking for work. These numbers are consistent with other studies which find that the overwhelming majority of sociology graduates are employed full-time (see, for example, Watts and Ellis, 1989).

Sociology alumni are employed in a wide variety of occupations from cook to pilot and just about everything in between. As was indicated in the literature, many of the respondents are employed in social services or business positions. Appendix $\mathrm{C}$ lists all the job titles reported by alumni on the returned surveys. Alumni were asked if their current job required a degree and about half stated that it did. Close to a third felt underemployed in relation to the level of education they had achieved. This was consistent 
with the finding of this research that most alumni feel they could perform their present job without their sociology degree.

The American Sociological Association advises sociology students that there are three major areas in which sociologists can find employment: teaching, research, and sociological practice ("applied" or "clinical" sociology). Figure 6 shows the national distribution of sociology majors in various fields as reported in the book Sociology (1995, Schaefer \& Lamm, eds.) compared with the information from the survey respondents.
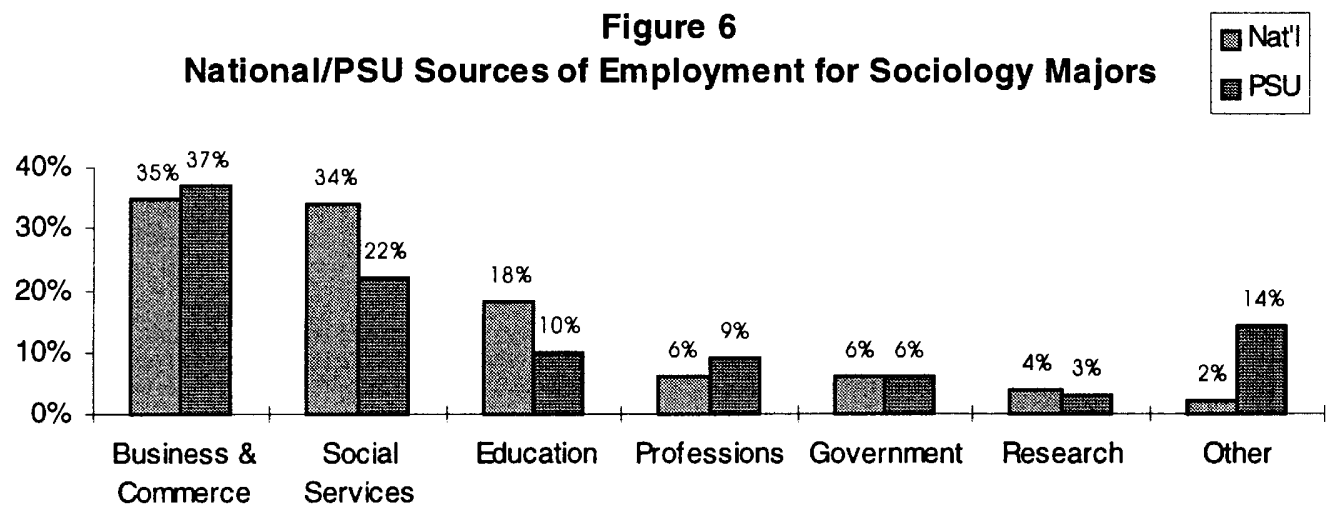

The majority of majors (both nationally and at PSU) are working in business and/or commerce, and not in the social services/education as one might expect. In fact, sociology majors from PSU are even more likely to work in business than in social sciences than the national average. This finding 
supports Watts and Ellis' (1989) research finding that sociology graduates are moving away from teaching and social service jobs and toward occupations in the business and private sector.

The incomes of alumni respondents was distributed somewhat normally, while current students were skewed toward lower incomes (see Figure 7) ${ }^{6}$. Watts and Ellis (1989) found that "the longer the period since graduation the greater the respondent's income" (p.299). That finding was duplicated here with a statistically significant positive relationship between year of graduation and income. For example, of those alumni who graduated before $1980,80 \%$ are earning more than $\$ 25,000$ per year. On the other hand, for those who graduated after 1980 , only $38 \%$ are earning more than $\$ 25,000$ per year.

\footnotetext{
${ }^{6}$ The lower income of current students is in part due to an increased likelihood of working part-time.
} 
Figure 7

Personal Income for Current Students and

Alumni

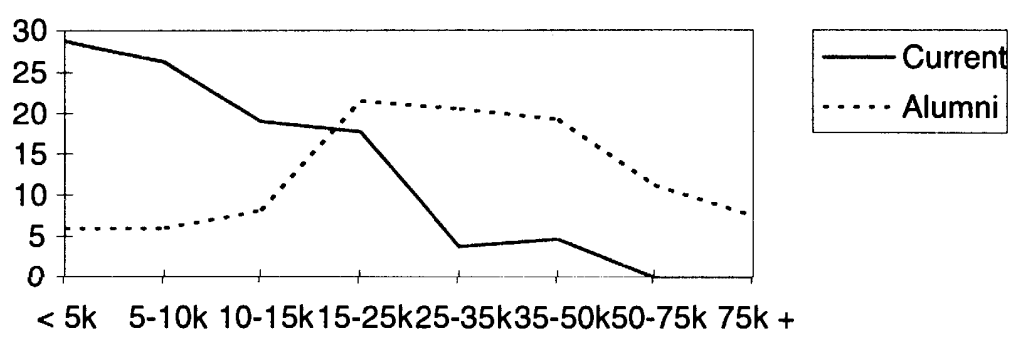

In Chapter 2 it was noted that the majority of students at PSU are nontraditional. Part of being non-traditional means that students must work while they attend school, as do the majority of current students. During a typical quarter, over seventy-five percent of current students are employed. The majority of those who work (28\%) are employed 20 to 29 hours per week, while less than $10 \%$ are employed less than ten hours per week.

Trying to work while attending school creates conflicts in students' lives and some of these conflicts are insurmountable. Some respondents lamented the lack of courses offered in the evening (especially required courses). As one current student noted, "As a full-time worker, I need to be able to complete my degree at night. As of now, this is not possible, so I am looking into other colleges." 
All respondents were asked how they paid the majority of their tuition. A third of current students pay the majority of their tuition with student loans while only $20 \%$ of alumni students report student loans as their major source of tuition payment. Otherwise, the two groups are similar with around $20 \%$ of both groups listing family loans as most important and around $20 \%$ also stating they used their own savings to pay for tuition. Close to half received help from their parents while the rest received help from their spouse or partner.

The Department of Education ${ }^{7}$ reports that only $15 \%$ of bachelor degree recipients intended to stop with their baccalaureate degree when asked about their plans one year after graduation. These early intentions are not borne out over time. For this survey, alumni were asked about the level of education they have obtained to date. Close to half stopped with the undergraduate degree while $29 \%$ have attended school beyond the bachelor's level without obtaining a degree. Twenty percent of alumni have earned a master's degree, while 3\% $(n=11)$ have obtained a Ph.D. Respondents were asked to indicate the field in which they earned their higher degrees, and a minority were in sociology $(n=9)$ and education $(n=9)$ while $7 \%$ of all alumni respondents $(n=24)$ had received a master's degree in some form of 
counseling. Other areas where alumni received master's degrees included Librarianship, Public Administration, Public Health, MBA, Ministry, and Urban Planning.

Over half of all alumni respondents intend to go on for more education at some point in the future ( $38 \%$ said no, $3.6 \%$ were not sure). Again, sociology was the minority choice of intended field, with $5 \%$ of those intending to go on listing sociology. An undergraduate degree in sociology appears to be a stepping stone into other academic programs that do not necessarily require (or offer) an undergraduate degree in the same field.

In order to examine the attitudes of alumni toward their jobs, they were asked to indicate their agreement with a series of Likert scale questions, with options ranging from "strongly disagree" to "strongly agree." Figure 8 displays the statements and the mean score for each; they are reported in the order of agreement. For the full text of the statements, please see Appendix A.

As Figure 8 demonstrates, alumni tend to feel positively towards their jobs. They were satisfied with the level of income they are earning and had little

\footnotetext{
${ }^{7}$ in the 1995 Digest of Education Statistics
} 
difficulty in finding their current jobs. While a majority felt their degree was useful in their work (66\%), less than half $(40 \%)$ felt they couldn't perform their job without their degree. This finding backs up the sentiment stated earlier that sociology degrees (and liberal arts degrees in general) are often not directly relevant to the jobs of their recipients.

Figure 8

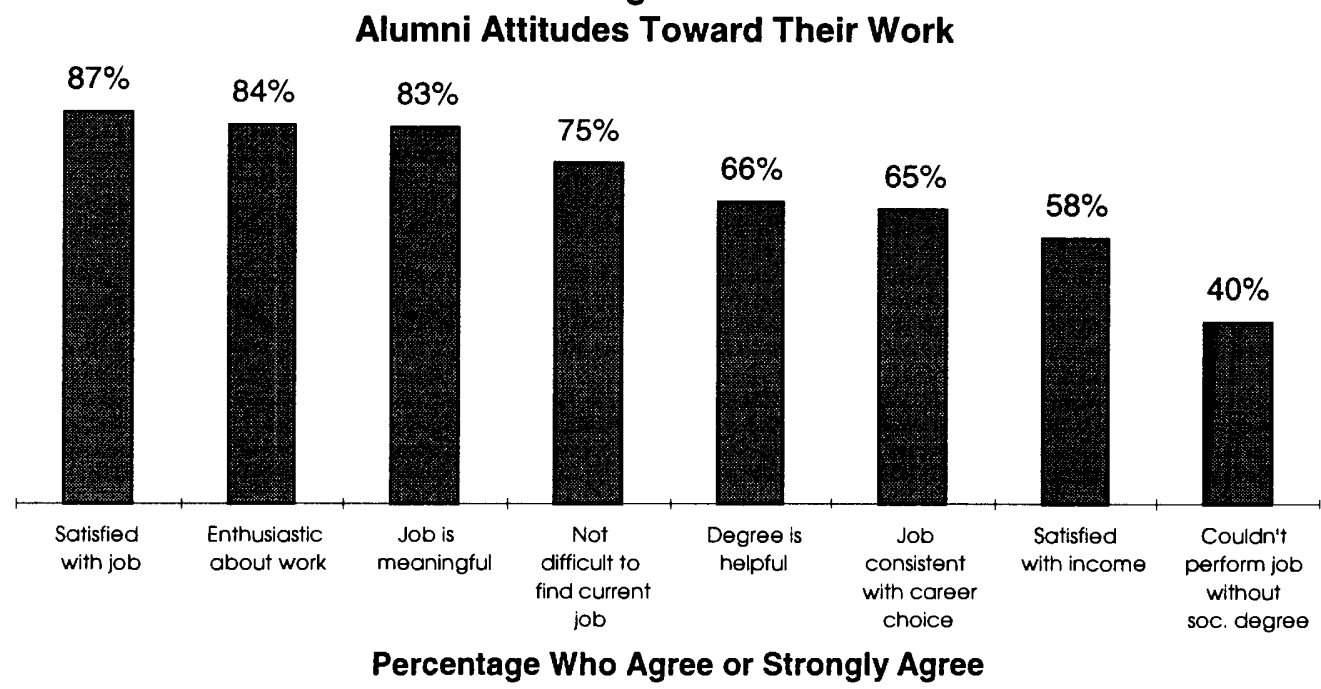

It was noted earlier that the majority of alumni are employed in white collar jobs. To ascertain what alumni do during their work day, they were asked to indicate how often they performed certain tasks while at work. Scores of "somewhat frequently" to "to a great extent" were combined and Figure 9 displays the results in descending order of frequency. As this chart shows, 
alumni spend the majority of their time in offices, working with computers and generating different types of documents - memos, letters, etc. Most alumni teach or train others in some capacity while on the job.

Figure 9

Tasks Performed on the Job by Alumni

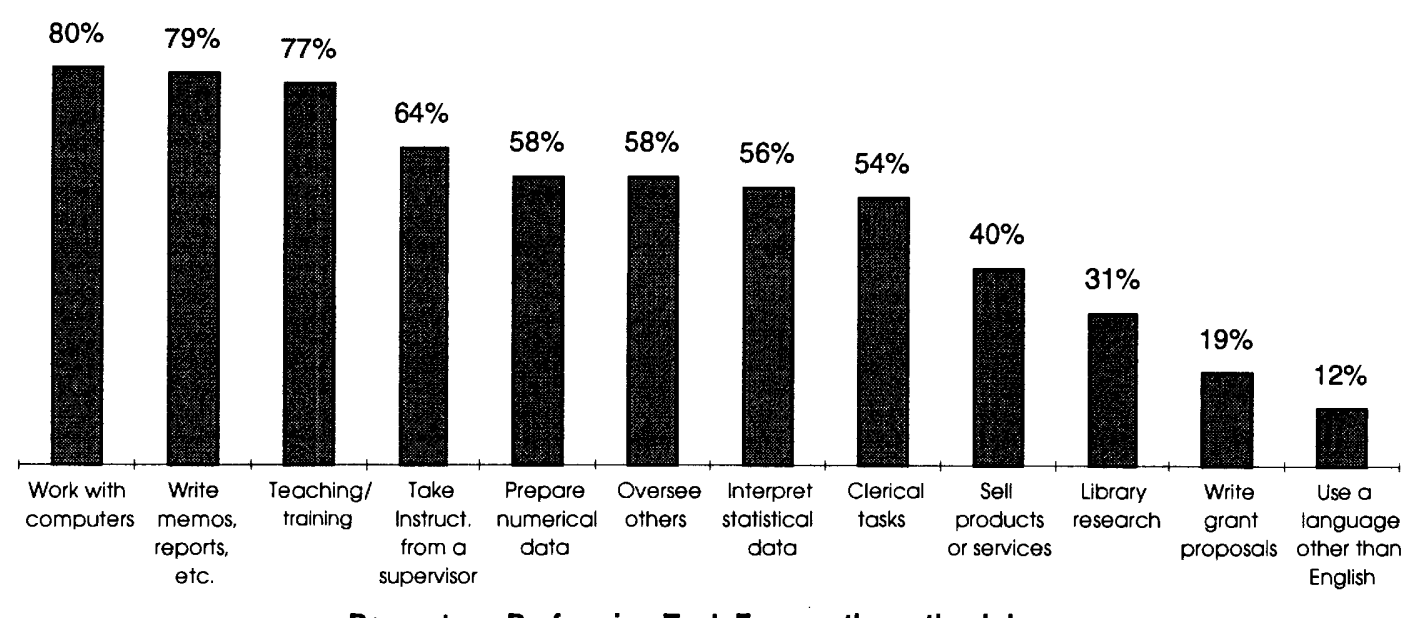

Percentage Performing Task Frequently on the Job

Part of understanding the experience of sociology alumni is ascertaining which courses and professors had an impact on them while they were in school. To this end, alumni were asked to list courses which had been "occupationally and personally valuable to you since graduation." Figure 10 lists those courses which were mentioned by at least five respondents. A full listing of courses is contained in Appendix E. 
Students place the most occupational value on the required methods course sequence offered at PSU. These two courses offer the most applied skills training in the undergraduate program. No course came close to this level of impact on the personal side.

\section{Figure 10}

\section{Sociology Courses Which Have Been Valuable To Alumni Since Graduation}

\section{PERSONALLY VALUABLE}

\section{OCCUPATIONALLY \\ VALUABLE}

$\begin{array}{llll} & \underline{\mathrm{n}=} & & \underline{\mathrm{n}=} \\ \text { Sociology of Women } & 18 & \text { Quantitative methods } & 57 \\ \text { Quantitative methods } & 16 & \text { Minority Groups } & 18 \\ \text { Theory } & 16 & \text { Social Psychology } & 17 \\ \text { Minority Groups } & 15 & \text { Theory } & 16 \\ \text { Social Psychology } & 14 & \text { Introductory Sociology } & 11 \\ \text { Deviancy } & 8 & \text { Criminology } & 11 \\ \text { Marriage and Intimacy } & 8 & \text { Sociology of Women } & 11 \\ \text { Criminology } & 6 & \text { Juvenile Delinquency } & 8 \\ & & \text { Medical sociology } & 6 \\ & & \text { Deviancy } & 5\end{array}$

The range of graduation years for alumni covered over thirty years, from 1962 to 1994 . The average year of graduation for alumni was 1980 .

However, Figure 11 shows that the distribution of year of graduation for alumni was not bell-shaped: 
Figure 11

\section{Alumni Year of Graduation}

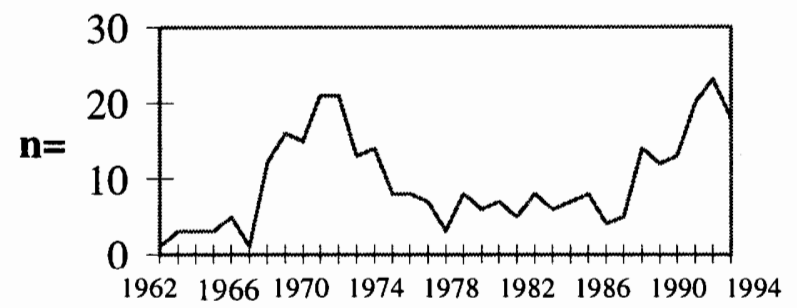

The majority ( $85 \%)$ of current students who responded to this research are enrolled full-time during a typical quarter. The 1994 University Fact Book shows that nearly half of all university students are enrolled part-time, and that sociology tends to have more part-time students than other disciplines. It was expected that the sampling frame for current students would produce the names of students who were likely to be more "engaged" with the university and therefore more likely to be full-time. Nearly all of the current students $(86 \%)$ transferred to PSU from another institution, with over half (58\%) coming from a community college and $29 \%$ from another four year institution.

Current students were also asked when they decided to major in sociology. Nearly $80 \%$ decided while in college, with $49 \%$ deciding when they were 
either freshmen or sophomores. If a student selected "other" for this question, they were asked to write down when they decided upon sociology as a major. These responses were all similar - students were working and made the decision to return to school to further their careers and decided on sociology before they returned. Wagenaar (1993) found that half of all sociology graduates declare their major in their junior or senior year (p. 358).

Current students were asked to report their class standing. Figure 12 below indicates the percentage of respondents for each class level as well as the distribution of class level throughout the university during the 1993/4 academic year. Again, this study examined only sociology majors who have officially registered their major with the school ${ }^{8}$.

\footnotetext{
${ }^{8}$ Again, students at Portland State University are not required to officially state their major until they are applying for graduation.
} 
Figure 12

Class Standing of Current Students

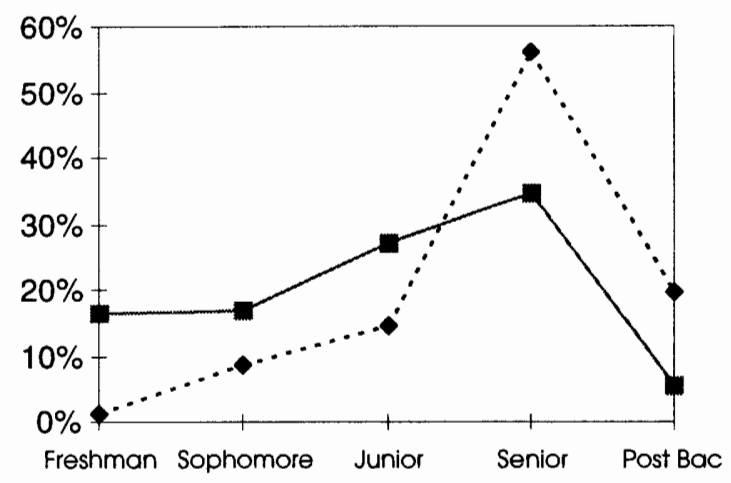

- - Survey Respondents

$\rightarrow-$ All PSU Students

As the chart above indicates, the respondents for this survey do not match the population at PSU. This finding bolsters the proposition that the sampling frame was biased towards those with a higher class standing. On the other hand, this finding was not completely unexpected considering that PSU has a limited number of freshmen anyway and that freshman are probably less sure of their major than seniors.

The motivations behind attending college were considered an important component for understanding how students would feel about the degree program. Current students were given four reasons for attending college and asked to rank them in descending order of importance in their situation. Only two of the reasons had enough "votes" to be considered consequential":

\footnotetext{
${ }^{9}$ The other two reasons were "It seemd like the best thing to do at the time" and "My parents wanted me to go."
} 
"To prepare me for a good job" and "To gain personal knowledge." Almost identical percentages of current respondents ranked these as being their primary reason for attending college. This finding is echoed throughout the research - sociology majors are not on a continuum between vocational and liberal arts. Rather, they want both issues addressed by their major and have a difficult time giving one more weight than the other.

Current students were asked to list what they would like to accomplish in the six months following graduation (see Appendix B). This was an unstructured question and 60 responses were received. The responses were read for themes and then categorized. Twenty-three percent of the respondents intended to continue with graduate school (e.g., "I intend to go on to graduate school after receiving my B.S. I hope to earn my MSW.). The Department of Education reported in 1991 that one year after graduation 35\% of all bachelor degree recipients and $42 \%$ of social science majors had enrolled in some type of further education.

Sixty-five percent intend to seek out or continue employment (e.g., "Find a job that is relevant to my interests," "Find meaningful employment which utilizes all I've learned"). The remaining respondents $(n=11)$ indicated plans 
which included both employment and graduate school. The full range of responses is contained in Appendix B.

In order to better understand why students decide to major in sociology, current students were presented with a series of Likert items (choices ranged from 1 to 5), some of which had space for comments or the listing of specific instructors/courses. The percentages for items ranked very important or extremely important to the decision to major in sociology are presented in Figure 13.

As this table indicates, sociology majors tend to "stumble into" their choice of degree programs and often chose the major based on personal interest rather than on future employment prospects. Quality of classroom instruction is a fundamental part of attracting majors to sociology. The high percentage of students who were drawn to sociology because they wanted to work in a helping profession also echoes the earlier finding that sociology majors tend to want to make a difference. 
I liked the sociological perspective

$88 \%$

I enjoyed my first sociology class

$79 \%$

I wanted to work in a helping profession

$79 \%$

I was impressed with the quality of classroom instruction

$64 \%$

Specific class at PSU

$49 \%$

Specific instructor at PSU

$44 \%$

Sociology classes were easy for me

$43 \%$

I thought a degree in sociology would make me more employable

$33 \%$

Required only one term of statistics

$21 \%$

Sociology classes fit into my schedule

$17 \%$

I knew someone who was majoring in sociology

$9 \%$

Students were then asked to list the top three most important reasons for their decision to major in sociology. Only two options made it into the double digits as the number one reason: I wanted to work in a helping profession (38.1\%) and I liked the sociological perspective (32.1). For the number two reason, the statement $I$ liked the sociological perspective was chosen the most (28.6\%) with I wanted to work in a helping profession and I enjoyed my first class nearly tied as the second most popular choice. The third place reason 
for majoring in sociology was Sociology classes were easy for me, however, the responses for third place were spread over 4-5 responses rather than being clustered around one or two.

If a specific class at PSU was an important factor in a current student's decision to major in sociology, they were asked to name the class. Figure 14 lists all of the responses for this item which were mentioned at least four times. This finding is consistent with importance placed in the literature on the introductory level course in sociology. It is often the first taste students have of sociology and even if it is not a major influence in their decision to major, it can lead them into taking other sociology courses which may influence them to major.

\section{FIGURE 14}

COURSES WHICH INFLUENCED CURRENT STUDENTS TO MAJOR IN SOCIOLOGY

Required Courses

Soc 204

$\underline{\mathrm{n}} \equiv$

Soc 205

5

4

Elective Courses

Social Psychology

Minority Groups

9

Marriage \& Intimacy

5

Juvenile Delinquency

5

4 
Alumni students were also asked why they decided to major in sociology. Unlike the current students, this question was presented to the alumni in open-ended form. While there was a wide variety of responses, certain themes emerged. Clearly interest is important - I changed my major every term the first two years of undergraduate school. I liked the sociology classes the best, so I majored in it - as well as furthering one's career goals I wanted to be a juvenile counselor. The full range of responses is presented in Appendix D and exemplifies the enthusiasm alumni continue to have for their major.

To ascertain how respondents felt about the sociology department at PSU and about sociology as a major, they were presented with a series of Likert items, with options ranging from 1 (Strongly Disagree) to 4 (Strongly Agree) ${ }^{10}$.

Figure 15 shows a comparison of percentages who strongly agreed with the item. Overall, both alumni and current students are very satisfied with the program, but they are pleased to different degrees. Generally, current students rate the department higher than alumni ${ }^{11}$.

\footnotetext{
${ }^{10}$ The items were worded slightly differently for alumni and current students to reflect their status.

${ }^{11}$ Two of the differences were not statistically significant at the .05 level - As a result of studying sociology, I understand society better than most people and Courses at PSU should put more emphasis on applied skills.
} 


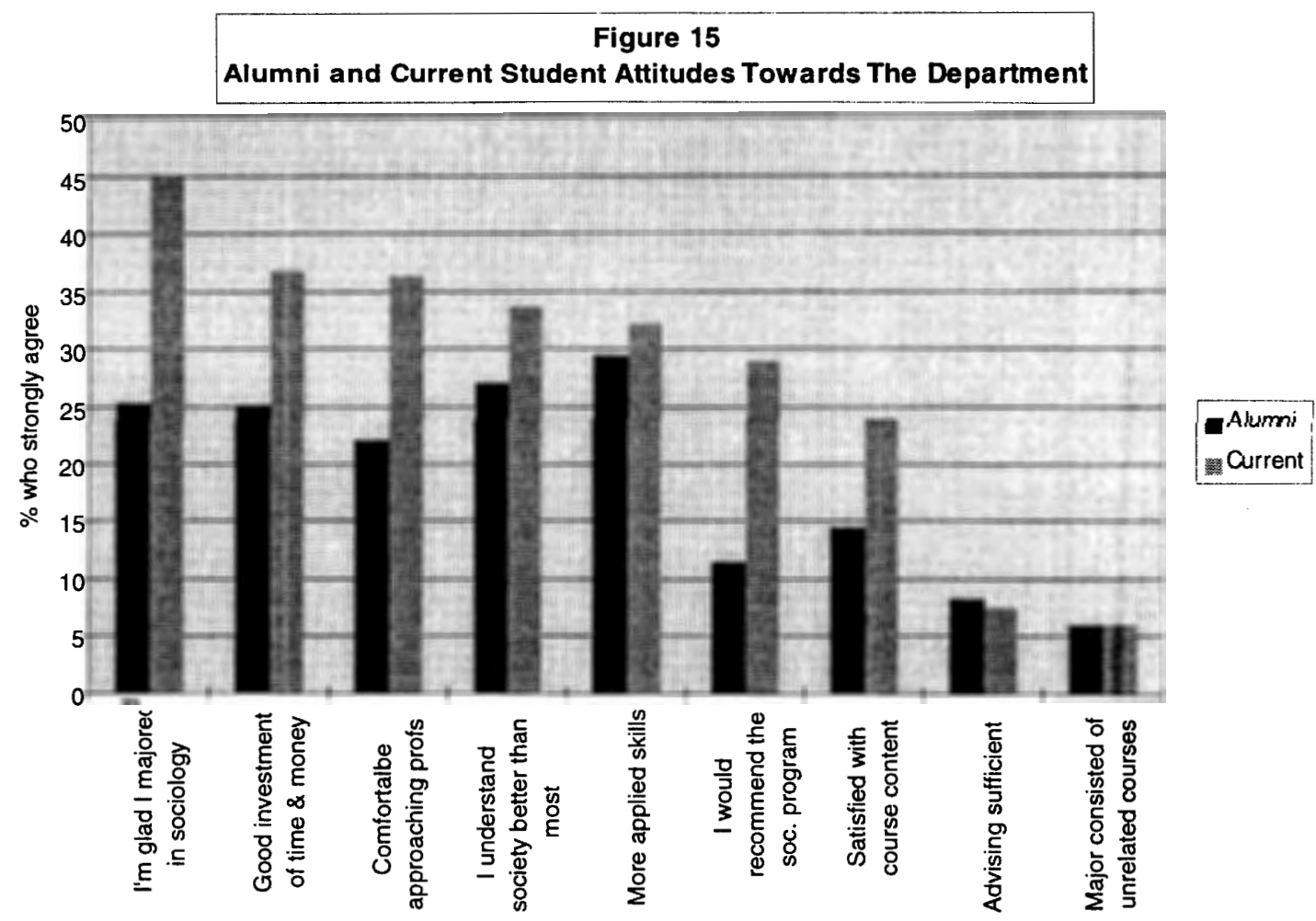

As noted earlier, an organizing theme of this research was the potential conflict between education for education's sake and the demands of the "real world." This conflict was measured by creating a score which would place respondents on a "liberal arts/vocational" continuum. It was felt that the more pragmatic a student was about what a sociology degree program should offer, the less satisfied they would be with the department at PSU. The assumption was that alumni and current students come into the program with this orientation intact, based upon their prior experiences and background. 
To measure the students' orientation toward the liberal arts/vocational question, a table was presented to respondents with a list of 14 skills or experiences one might find in a sociology undergraduate program. Alumni were asked Based upon your experiences since graduation, how much importance would you place on the following areas and current sociology majors were asked If you were to design an undergraduate program to best suit your needs, how much importance would you place on the following areas.

Seven of the items were intended to measure a respondent's orientation towards liberal arts while the other seven were vocationally oriented. Respondents were asked to indicate the level of importance of each of these skills or experiences on a scale from 1 to 5, with 1 meaning "Not Important At All" and 5 "Extremely Important." The fourteen items were distributed randomly in the table. Current students and alumni differed to a statistically significant level on all but two of the items ${ }^{12}$. Current students tend to feel most areas (both liberal arts and vocational) are more important than alumni. This may reflect a certain anxiety about the future expressed by current

\footnotetext{
${ }^{12}$ Liberal arts: Development of critical thinking skills; Vocational: Learning interview skills
} 
students when they were asked what their plans were in the first six months after graduation (see Appendix B).

The only statistically significant area of liberal arts items which alumni feel is more important than current students is "writing skills." As noted earlier, the majority of alumni use writing skills on the job. Items which are focused specifically on sociological topics tend to be seen as less important by alumni, as was preparing for graduate school.

Figure 16 - Liberal Arts Oriented Items Comparison Between Alumni and Current Students

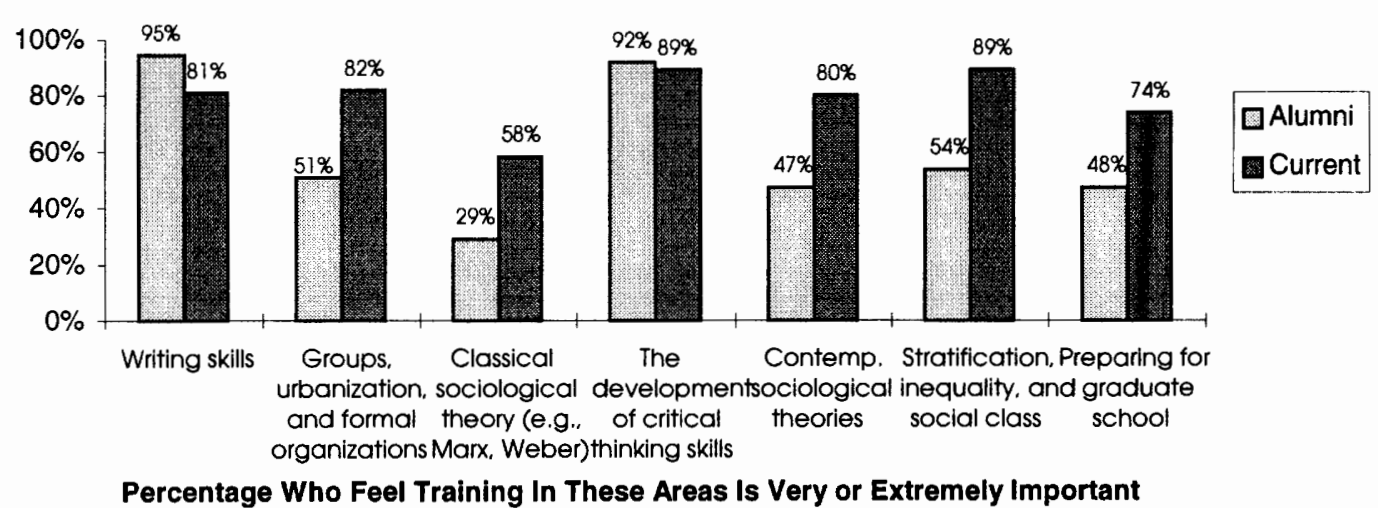

The other seven items in the table were intended to measure vocational orientation (see Figure 17). Again, alumni students placed a great deal of importance on a skill they use frequently on the job - in this case, computer 
skills. Current students want internships, but alumni seem to feel they are less important (chances are, of course, they didn't have one). Reading statistical data is seen by alumni as much more important than conducting research. This, again, is consistent with what they do on the job. Both groups feel that learning what jobs are available to sociology majors is an important component of the department.

Figure 17 - Vocationally Oriented Items Comparison Between Alumni and Current Students

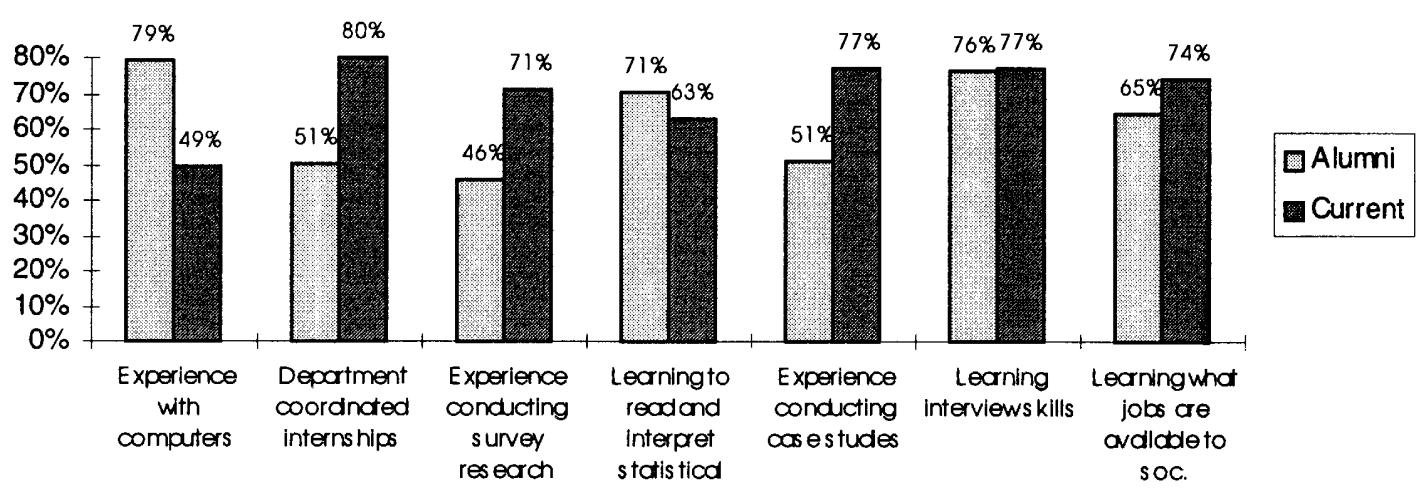

Percentage Who Feel Training in These Areas Is Very or Extremely Important

Finally, respondents were also asked to rank the top three components of a sociology department (see Figure 18). As the table shows, when compared with alumni, current students displaced "writing skills" with "learning what jobs are available to sociology majors." However, both groups felt (by a 
strong margin) that the development of critical thinking skills was the most important feature of a department.

\section{Figure 18}

Most Important Component of a Sociology Undergraduate Program

\begin{tabular}{c|c} 
Alumni & Current \\
\hline Develop critical thinking skills (37\%) \\
Writing skills (19\%) \\
Computer skills $(13 \%)$ & $\begin{array}{c}\text { Develop critical thinking skills (29\%) } \\
\text { What jobs are available }(12 \%)\end{array}$ \\
Computer skills $(7 \%)$
\end{tabular}

\section{Conclusion}

This chapter presented an examination of the data gathered from the surveys mailed to all alumni and current students. A profile of the respondents was presented as well as an analysis of the questions used to measure the respondents feelings about the department, the sociology major, and their jobs. The next chapter analyses the components of the model presented in Chapter 3 and examines the specific hypotheses generated for this research. 


\section{ChAPTER V.}

\section{ANALYSIS}

\section{Introduction}

This chapter begins with a description of the method used to measure the main dependent variable - degree program satisfaction. It follows with a discussion of each of the hypotheses and the overall fit of the data to the model described earlier.

\section{Measuring Degree Program Satisfaction}

To measure degree program satisfaction, a series of statements was created and presented to the respondents in Part I (question 3) of both surveys. This section was comprised of nine Likert questions intended to measure degree program satisfaction (see Figure 15, Chapter 4). The respondents were asked to indicate their agreement with statements such as, My undergraduate sociology degree was a good investment of my time and money. Both current students and alumni were asked these questions. Current students were asked to consider their experiences so far. 
The initial problem was to determine if these statements were indeed measuring "degree program satisfaction". To this end, a factor analysis was performed on the nine items. The analysis uncovered two factors at work with the majority of the statements loading high on this factor which was labeled degree program satisfaction.

Two of the statements did not load high on this factor and were not used to measure degree program satisfaction. These statements were Courses at PSU should put more emphasis on applied skills and My sociology major consisted of a collection of more or less unrelated courses (which loaded negatively on the factor). This factor appears to be a measure of usefulness of the degree or pragmatism and was not used to measure degree program satisfaction.

The analysis showed that the seven remaining items were measuring the same factor which was labeled degree program satisfaction. The next step was to create a degree program satisfaction score for each respondent. To this end, the seven statements were added together and divided by seven. This created a scale with a range from 1 to 4 , with 4 being the highest possible level of degree program satisfaction. A score of four meant the respondent strongly agreed with all seven statements while a score of 1 indicated they strongly 
disagreed with all seven. The average score was 2.95 and the range was 1.29 to 4.0. With this measure constructed, the hypotheses could be tested.

\section{Examination of Hypotheses}

\section{Hypothesis 1}

Figure 19 below shows a comparison of degree program satisfaction scores between current students and alumni. This chart indicates that current students are more heavily clustered toward scores indicating higher degree program satisfaction.

Figure 19

Degree Program Satisfaction Scores for Current Students and Alumni

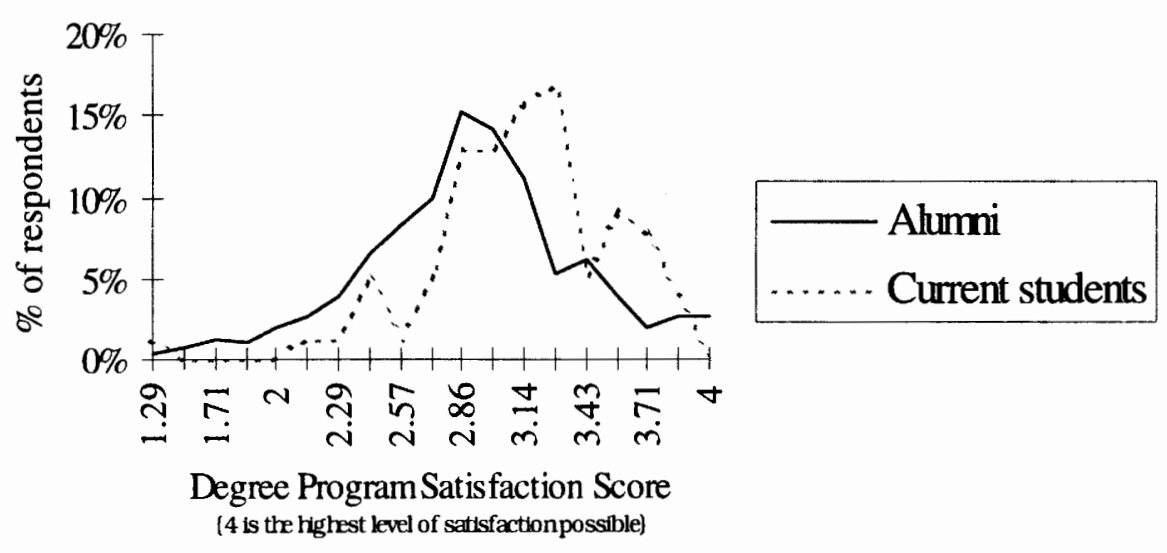


Hypothesis 1 stated that Current students are more satisfied with their degree than alumni and was substantiated via a comparison of means (see Figure 20). A t-test of means shows that the mean score for alumni (2.91) is lower than the mean score for current students (3.12) at the $p<.05$ level, indicating a lower level of degree program satisfaction.

Figure 20

Comparison of Average Degree Program Satisfaction Score for Alumni and Current Students Higher scores indicate stronger vocational orientation
\[ (p>05) \]

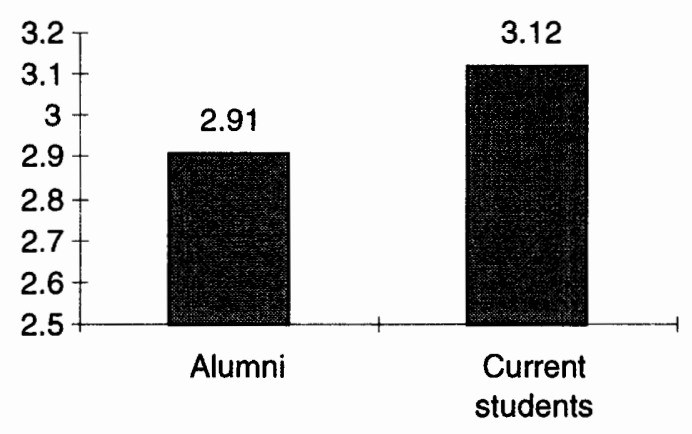

The rest of the hypotheses are presented pictorially in the following model. As noted earlier, the model is used to represent the sources and direction of influence on degree program satisfaction: 


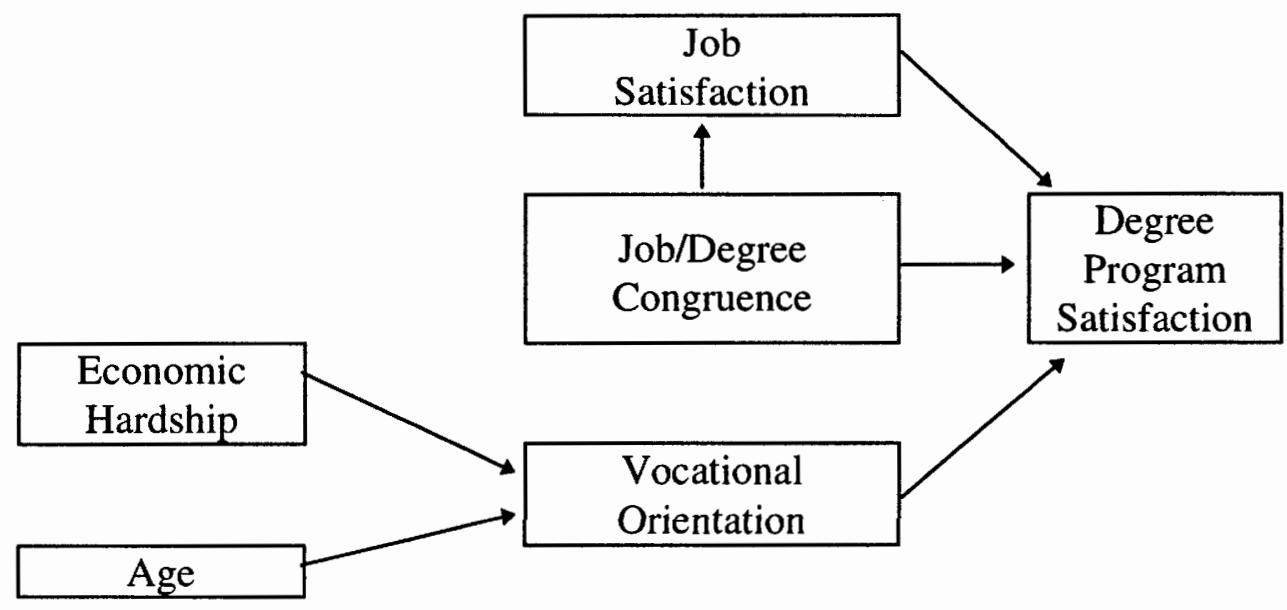

Due to differences in the surveys (e.g., the job/degree congruence variable is intended for employment after receiving the degree), the complete model above can only be examined for alumni -- the part of the population that was of greater interest for this study. However, where possible, current student input is compared with alumni.

While the model above implies a path analysis, due to the ordinal nature of most of the data, means testing (and correlations where possible) were used predominantly as a method for rejecting or failing to reject the hypotheses. The final section of this chapter briefly presents the model with its path coefficients. Before discussing the specific findings related to degree program satisfaction, the concept of a vocational/liberal arts orientation, and its influences, is discussed. 


\section{Liberal Arts/Vocational Scores}

The intention of the liberal arts/vocational score is to ascertain if students want their undergraduate degree to lean more towards a liberal arts orientation or towards a more vocational orientation. The continuum on which the orientation was measured was presented earlier:

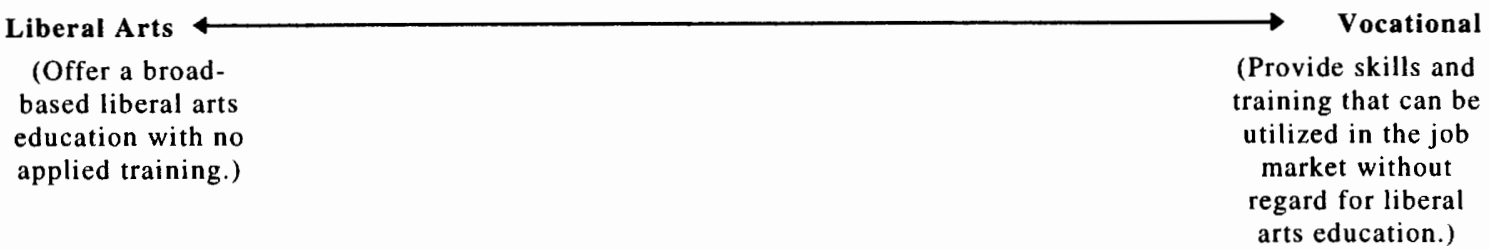

(Provide skills and training that can be utilized in the job market without regard for liberal arts education.)

As discussed in Chapter 4, alumni and current students were presented with a table of items to which they assigned importance for an undergraduate degree program. Half of these items were intended to be liberal arts oriented and the other half were vocationally oriented (see Figures 16 and 17).

Factor analysis was used to investigate the efficacy of the items - did they indeed measure the respondents' liberal arts/vocational orientation? Analysis showed that the 14 statements did not all measure orientation as intended. For example, two of the statements which were expected and intended to measure vocational orientation (and load high with other vocational statements) were Experience conducting survey research and Learning to 
read and interpret statistical data. These variables loaded together on the same factor, a factor which did not contain any other variables. These quantitative skills did not vary with the other applied skills (which load on a single separate factor). They were not included in the final liberal arts/vocational scale.

Another factor contained what was intended to be the strongest liberal arts factor -- The development of critical thinking skills -- along with Writing skills and Experience with computers. As noted in Chapter 4, these three traits are the most important components of a sociology program for alumni respondents. These departmental characteristics did not vary with the other variables as projected and were not included in the final liberal arts/vocational scale.

The remainder of the traits varied together as anticipated and were combined to create the vocational/liberal arts scale. The liberal arts components of the scale were multiplied by -1 to contrast them with the applied components when they were combined. This created a scale from -5 to 5 . A score of -5 would be a pure liberal arts orientation, a score of 5 would be a pure vocational orientation and 0 was the fulcrum between the two ends. Figure 21 shows the distribution of these scores for all respondents. 
Scores to the right of the broken line $(0.0)$ represent a strong vocational orientation, while scores to the left indicate a stronger liberal arts orientation.

Figure 21

Distribution of Orientation Scores

(The larger the number, the stonger the vocational orientation)

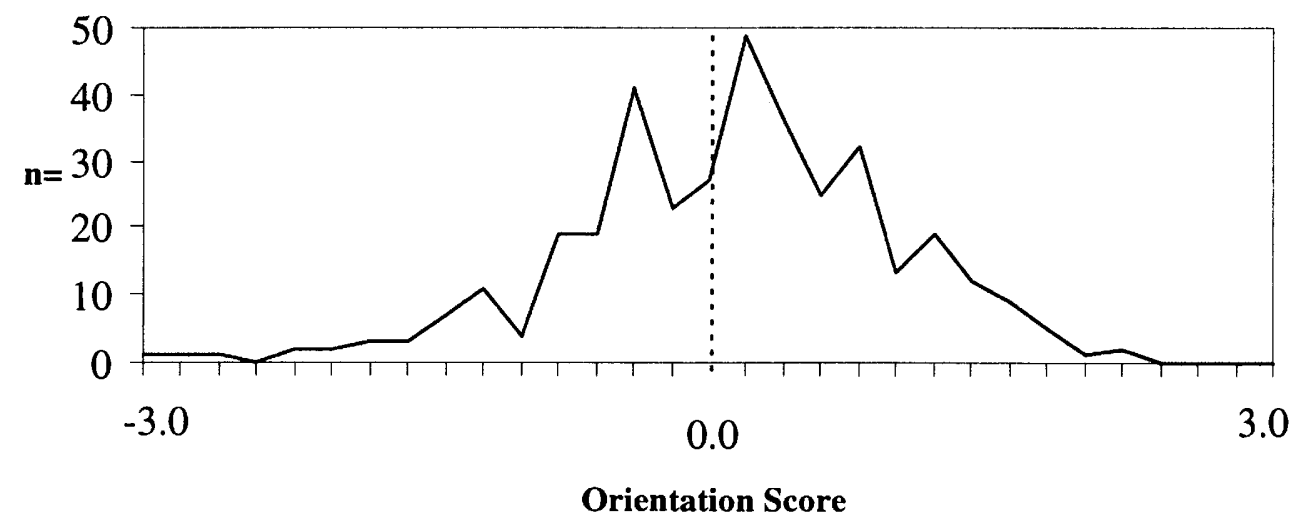

\section{Explaining vocational/liberal arts orientation}

This section is concerned with trying to understand what explains the position of a respondent on the vocational/liberal arts continuum. It begins with a discussion of the hypotheses tested and continues with an examination of other variables and their influence on orientation.

\section{Hypothesis 2}

The older a respondent is, the more likely they are to have a vocational orientation. 
Linear regression, using age to predict orientation, indicates the rejection of Hypothesis 2 for both alumni and current students $\left(r^{2}\right.$ for alumni was .00 ; for current students .02). Using t-tests to compare the mean orientation scores of respondents by age showed the same result. There was no statistically significant difference in orientation score by age. For example, when the mean orientation score for alumni was compared using the modal age as the cut-off point, the difference between the two scores was only .04 . Hypothesis 2 is rejected for both alumni and current students. There is no relationship between age and tendency towards a vocational orientation.

This hypothesis was generated with the expectation that the longer a person had been in the job market, the more emphasis they would feel should be placed on applied skills. Perhaps since sociology majors tend to be older than other students, the more appropriate measure would have been years since graduation as opposed to age. However, upon testing, the number of years since graduation also failed to correlate with a stronger vocational orientation. 


\section{Hypothesis 3}

The more hardship one endures to obtain their education, the more likely one is to have a vocational orientation.

The level of hardship was measured by looking at the way in which respondents paid tuition. The assumption was that the more debt one had to incur to pay for an education, the more concerned one would be about gaining vocational skills - a sort of cost-benefit analysis. Respondents were asked how they paid the majority of their tuition. The responses to this question were separated into two categories: 1) their tuition was paid mostly by themselves (higher degree of hardship) or 2) their tuition was paid mostly by others (lesser degree of hardship). A means test was performed to examine the relationship between the hardship incurred to attend college and a stronger vocational orientation (see Figure 22).

Figure 22

Comparison of Average Orientation Scores* By How the Majority of Tuition Was Paid

\begin{tabular}{|l|c|c|c|}
\hline & $\begin{array}{c}\text { How The Majority of } \\
\text { Tuition Was Paid }\end{array}$ & $\begin{array}{c}\text { Average } \\
\text { Orientation } \\
\text { Score }\end{array}$ & Significance \\
\hline Alumni & Self & .3546 & .022 \\
\hline Other & .0909 & .571 \\
& Self & -.1024 & -.2233 \\
\hline
\end{tabular}

* Scores above 0 indicate a vocational orientation; below 0 , liberal arts 
The results of hypotheses testing in this situation were different for the alumni and the current students. Alumni students showed a statistically significant difference in their tendency toward a vocational orientation. As expected, those who paid the majority of their tuition themselves had a stronger vocational orientation. This finding supports the idea that students who are paying for their own education have higher expectations for the usefulness of their degree in the workforce.

On the other hand, current students did not have a statistically significant difference in vocational orientation based upon how they paid the majority of their tuition. Here, the idea that students who are paying for their own education have higher expectations for the usefulness of their degree in the workforce is not supported. It is unknown why the finding for alumni is not duplicated with the current students.

\section{Other Explanations for Liberal Arts/Vocational Orientation}

While age and financial hardship were the variables hypothesized to influence orientation, other variables were examined out of curiosity. These variables and their relationship to orientation were measured using t-tests. 


\section{Parental Education Level}

As noted earlier, all respondents were asked the educational level of their parents. The scores assigned for each parents education level (1 being less than high school, 7 indicating a graduate degree) were added together and divided by two. As with age, the mode was used to create groupings for comparison purposes. This procedure found no statistically significant relationship between the education level of parents and the orientation of the respondent. Linear regression showed no relationship between the two variables. Alumni and current students were separated and examined with the same result. Also, the parental education levels were examined separately and also showed no relationship.

\section{Gender}

Gender was found to have no statistically significant relationship to vocational/liberal arts orientation for either alumni or current students. I was surprised by this. I would have expected (stereotypically, of course) that women would be less concerned with the applied side of the degree. I don't have an explanation for this lack of relationship. 


\section{Income}

Income was hypothesized to increase a tendency towards a vocational orientation. For alumni students, income and a tendency toward a vocational orientation score are inversely related. For current students, the relationship goes the other way. However, neither of these findings is statistically significant at the .05 level. The next hypothesis moves from the vocational/liberal arts orientation to explaining degree program satisfaction.

\section{Hypothesis 4}

The more satisfied a student is with their job, the more highly they will rate their degree program satisfaction.

Job satisfaction was measured by adding together the scores on three variables:

I am satisfied with the income from my job.

Other than a paycheck, my current job has little meaning for me. Most days I am enthusiastic about my work.

The scores were added together and divided by 3 to create a scale from 1-4 with 4 being the highest possible level of job satisfaction. Current students 
are excluded from this hypothesis as their job satisfaction level was not measured.

A comparison of means shows that there is a small but statistically significant difference in orientation based on level of job satisfaction. Those who are more satisfied with their jobs are more satisfied with their degree (average of 3.02 for those who are more satisfied with their jobs as opposed to 2.81 for those who are less satisfied). This hypothesis is not rejected, although it is noted the relationship is quite weak.

\section{Hypothesis 5}

The stronger a respondent's orientation to liberal arts, the more satisfied they will be with the degree program.

Both alumni and current students can be examined for this hypothesis. A comparison of means for all respondents shows that when orientation is separated by the mode into liberal arts and vocational, the average satisfaction score for liberal arts respondents is higher (3.10) than for vocational oriented respondents (2.81). This difference is statistically significant. However, when alumni and current students are separated, it is shown that current students' orientation does not have any statistically 
significant influence on their degree satisfaction. Alumni, on the other hand, show a positive relationship between a liberal arts orientation and degree satisfaction. The average degree satisfaction score for those with a liberal arts orientation is 3.1 while for those with a more vocational orientation show an average of 2.7. Linear regression echoes this weak, but present (and statistically significant) relationship $\left(\mathrm{r}^{2}=13\right)$. This hypothesis is shown to have some merit for alumni and is not rejected.

\section{Hypothesis 6}

The more useful a respondent feels their degree is in their current employment, the more highly they will rate their degree program satisfaction.

Hypothesis 6 cannot be tested on current students because they were not asked the necessary questions about their current employment - the interest was in employment after graduation. A variable to measure the usefulness and relevance of their sociology degree to alumni was created. It was comprised of the following variables: 
My sociology undergraduate degree is very helpful in my present job.

I could just as easily perform my current job without an

undergraduate degree in sociology. ${ }^{13}$

The scale was used to predict degree program satisfaction using means testing.

Comparison of Degree Program Satisfaction Mean Scores by Job/Degree Congruence

\begin{tabular}{|l|c|c|c|}
\multicolumn{1}{l|}{} & Cut-off Point (mode) & $\begin{array}{c}\text { Mean } \\
\text { satisfaction } \\
\text { Score }\end{array}$ & Significance \\
\hline \multirow{3}{*}{ Alumni } & $\geq 1$ “degree useful" & 3.1 & .000 \\
& $<1$ "degree not so useful” & 2.8 & \\
\hline
\end{tabular}

As the table above shows, those respondents who felt the degree was useful in their jobs have a higher average rating of the department. This hypothesis is not rejected.

\section{Hypothesis 7}

The final hypothesis is intended to measure the relationship between job/degree congruence and job satisfaction. Specifically:

\footnotetext{
${ }^{13}$ The scores for this variable were mutliplied by $(-1)$. This procedure allowed for higher scores on both variables to indicate a higher level of usefulness/relevance.
} 
The more useful their degree is in their current job, the more satisfied they will be with their job.

These two variables are indeed positively correlated $\left(r^{2}=.20\right)$ at the .05 level. Means testing shows that those who have a higher level of congruence between their degree and their job are happier with their jobs. Those who have a higher level of congruence have a higher average score on job satisfaction (5.5 as opposed to 3.8$)^{14}$.

\section{Using Path Analysis to Examine the Model}

While the model used to organize this work lends itself structurally to path analysis, the variables used do not. The fact that they are ordinal variables with limited range of options (in most cases only four options are available) limits the variance and hampers a regression analysis. However, for interest as well as to complement the previous examination, the model was examined and the values are listed below. As only alumni were asked all the relevant questions to the model, the model is created using only their responses.

\footnotetext{
${ }^{14} 8$ is the highest job satisfaction score possible
} 


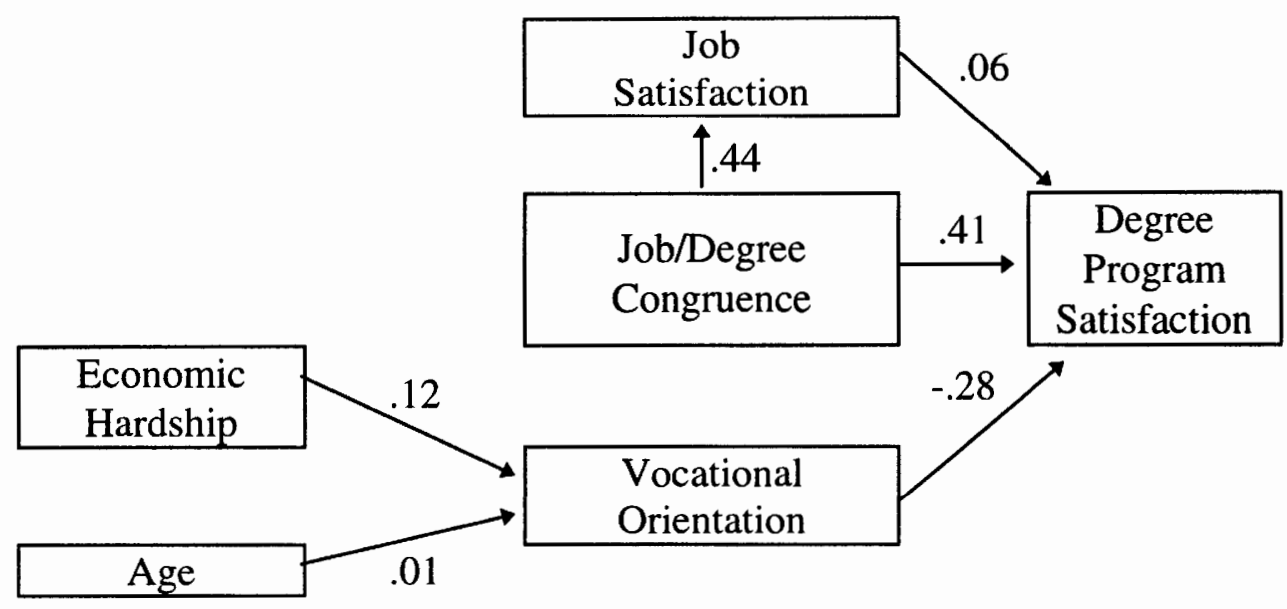

An important factor in understanding degree program satisfaction is how useful a graduate feels their degree is in their current job. As the path coefficient shows, the more relevant their degree is to their work, the more satisfied they are with the program. Also, the more relevant to their work their degree is, the happier they are in their jobs. Job satisfaction itself is not very useful in understanding degree program satisfaction. The more one thinks a degree program in sociology should offer applied training, the lower their satisfaction level with the department. Finally, increased financial struggle increases a tendency towards a vocational orientation and age is not useful in predicting vocational/liberal arts orientation. 


\section{ChAPTER VI.}

\section{DISCUSSION AND RECOMMENDATIONS}

\section{Introduction}

This chapter begins with a summary of the profile of the respondents presented in Chapter 4 and the analysis presented in Chapter 5. It then continues with the conclusions drawn from this research and the recommendations for further study.

\section{Summary of Respondent Information}

The majority of the respondents in this research were alumni as opposed to current students. The typical respondent is female (the ratio of females to males being higher for current students than for alumni) and is 39 years old. About half of the respondents had at least one parent with a college degree. The majority of alumni are employed full-time in a wide variety of occupations. Most current students work while attending school.

Current students earn far less than alumni (they also are more likely to work part-time). About half of the alumni stopped at an undergraduate degree 
while the majority of those who continued did so in a field other than sociology.

Alumni appear to be fairly satisfied in their jobs and appear to be performing mostly white collar jobs involving computers and writing - skills they rank as important attributes of a good department. The majority of current students are full-time seniors who transferred from another institution, and chose to attend college to gain personal knowledge and to prepare for employment. Also, the majority of current students plan to find employment in the six months after graduation. The hypotheses are examined in the following section.

\section{Summary of Analysis}

The following table summarizes the analysis done for this research.

Asterisks mark the questions that were not relevant to current students. 
Figure 23

Summary of Hypotheses Testing

\section{Current}

Hypothesis

Alumni

Students

1. Current students will be more satisfied with the degree program than alumni students.

Confirmed

2. The older a respondent is, the more likely they are to have a vocational orientation.

Rejected

Rejected

3. The more hardship one endures to obtain their education, the more likely one is to have a

Confirmed

Rejected vocational orientation.

4. The more satisfied a student is with their job, the more highly they will rate their degree program

Confirmed satisfaction.

5. The stronger a respondent's orientation to liberal arts, the more satisfied they will be with their

Confirmed

Rejected degree program.

6. The more useful the respondent feels their job is in their current employment situation, the more

Confirmed highly they will rate their degree program satisfaction.

7. The more useful the degree is to their current job, the happier they will be with their job.

Confirmed

\section{Discussion and Recommendations}

The research conducted herein was an exploratory step in understanding what sociology graduates would like to see in an undergraduate program. The model created to explain degree satisfaction was not found to be particularly 
useful. No hypothesis for current students was shown to be valid except the fact that they tend to be more satisfied than alumni.

It was assumed that alumni, having been out in the workforce, would be more pragmatic (vocational) about what a degree program should offer. This was not borne out by the analysis. Many of the relationships which were not rejected were quite weak.

The idea of a vocational/liberal arts orientation was not clearly supported. The continuum was based upon the anticipated finding that students and alumni would have an opinion about what the focus of the department should be and that opinion would be focused towards liberal art or vocationalism. They do, indeed, have an opinion about what the focus of the department should be, but it is not on a continuum between liberal arts and applied skills. They want the focus to be on both.

Alumni and current students strongly feel that the most important job of the department is to teach critical thinking skills. After this, they want jobuseful skills such as writing and computer skills. Regarding the most applied training offered by sociology -- research methods -- alumni feel it is more important to be able to understand quantitative research than it is to conduct 
it. The skill of interpreting research is much more commonly used on the job and few sociology graduates $(3 \%)$ report being employed in positions where they conduct research.

There are a number of recommendations that stem from the finding that alumni need to be able to understand research more than they need to be able to perform it. Most lower division courses use secondary sources to present course information. It might be useful to have some sort of brief, but continuing, discussion about the source materials for introductory texts. Who writes them? How are they chosen for each class? This would teach students early on how to use a critical eye when examining research, especially secondary sources.

Upper division courses often use primary sources of information and this presents the opportunity to discuss how conclusions are reached in research and some pointers on determining the merits of research. An off-shoot of this topic is the lack of training in how to locate research in the library. Many students are unaware of even the most basic research tools such as abstracts and indices. A departmental information sheet on finding 
sociological research would be of great benefit to upper division undergraduates and would benefit them after they leave the university.

Another suggestion is to present some of the findings in this research to current students in courses which are required for sociology majors. Current students are anxious about finding work after they graduate and even seeing the list of positions in which alumni students are employed might be helpful. Also, the list of skills used by sociology majors would show them where they might focus their energy while in school.

Addressing the dual goal of sociology majors is a difficult task. Ruggiero and Weston (1985), who examined the idea of a liberal arts/vocational departmental focus, believe that students and faculty may be at odds about the purpose of a degree. Their recommendation is that departments maintain a strong liberal arts focus, while at the same time exposing students to "real work settings through internships, providing job counseling, and helping students to develop the necessary skills to obtain jobs..." (p.228). Faculty, they believe, should work to "emphasize the interrelationships between theory and application in both applied and traditional sociology courses" (p.229) to help the student's see sociology's role outside of the classroom. 
They recommend advising students to take courses in other departments which might help to round out their vocational potential and to develop a portfolio containing their best work. Also, they recommend having graduates come and speak to undergraduates. All of these suggestions are consistent with the findings of this research and would be welcomed by undergraduates.

All of the surveys contained an open-ended question asking students and alumni to suggest ways the department could be improved ${ }^{15}$. The complete list of comments is found in Appendix F. Possibly the biggest complaint students had is with the advising system (or lack thereof) in sociology. Only $54 \%$ of current students and $45 \%$ of alumni agreed they had received sufficient advising from the department. Many of the recommendations for departmental improvement revolve around the need for better advising.

This problem is not isolated. The Report to the University by the PSU Committee on Undergraduate Student Retention (1993) noted that "[t]he quality and availability of academic advising were named most frequently as areas in need of improvement" (p. v). The fact that PSU overall has poor advising increases the need for a formalized advising program. The department may be silently losing students who are new to the college

\footnotetext{
${ }^{15}$ See Appendix F for a complete listing of all comments.
} 
experience or less assertive and to whom the idea of "just pick someone and go and talk to them" is overwhelming. As one current student noted:

There is little advising available, and even worse, students must initially pick an advisor...A student cannot say "I'm interested in sociology and urban planning, how do I maximize my training?" without getting a blank stare and an uninformed answer.

Rifenbary (1995) argues that older students, especially women reentering academia have a "strong need for guidance [and] information about procedures, major fields and employment prospects" (p.2). As noted earlier, the majority of sociology majors are women and they tend to be older than the average liberal arts student and older than the average student at PSU.

If a more substantial advising program is offered, it would ideally include some vocational counseling. Again, a basic departmental information sheet presenting the types of jobs sociology alumni are working in and the skills current students should focus on obtaining in college would be of great help. Kressel (1990) argues that we would benefit students by giving them a realistic expectation of the major. He states that a social science major may not be the best choice for all students "especially those with high subjective 
income needs who do not anticipate going to graduate school or obtaining employment related to the major" (p.226).

\section{Other Recommendations}

There are numerous recommendations in the literature on how to improve sociology programs. While these recommendations do not stem from or relate directly to the research presented herein, a brief mention of a few is included in the anticipated interest of the reading audience.

A course in career and professional development may help students structure their choices in terms of courses and experiences and help them improve their post-graduation marketability (Kressel, 1991). Cover (1990) makes an interesting recommendation: in order to make statistical methods classes more relevant and to overcome skepticism about research on the part of the students by having them replicate classic studies in methods classes as opposed to having students develop new studies.

McGee, et al, suggest that introductory instructors consider what they want the students to learn and then seek out materials which will help them achieve that end. They specifically suggest using texts such as Susser's Norman Street and Rubin's Women of a Certain Age as texts which can help 
engage students in the study of sociology and teach them about important sociological concepts in ways which are grounded in life experiences.

Muir (1994) reported "students in two introductory courses using conventional lecture methods showed no gain in methodological knowledge" (quoted from Cover, p. 231). While those who learned in more hands-on courses showed significant gains. A large number of sociology alumni specifically mention Sociology $384 / 5$ being important to them professionally and personally after graduation and along with teaching applied skills, these courses require the active participation of students.

Conklin and Robinson (1985) note that "The physical sciences all include practical experience gained in a laboratory...Theory is taught in the classroom and confirmed through carefully controlled replications." (p.49). Kremer \& Bringle (1990) found that experience with research made students 1) more likely to choose a research oriented career; 2) improve their research skills; and 3) more likely to apply to and be accepted at graduate schools with high research productivity.

In summarizing the research into student expectations and recommendations for improvement, Ruggiero and Weston (1985) note that "Students...want 
faculty to place more emphasis on academic career counseling, provide training in management, public speaking, and computer programming, and integrate academic course content with career plans through internship placements" (p.226).

\section{Recommendations for Further Study}

McGovern and Carr (1989) recommend that a "department begin with descriptive surveys about their alumni and move to more complex evaluation instruments after the first results are available (p. 56). Over the years there have been attempts on the part of the sociology department at PSU to define who the alumni are and what they are doing. At this point, more in-depth focus is warranted.

A series of case studies of alumni career paths would be of interest both to the department and to its current majors. Also, a joint focus group of alumni and current students could be used to better understand the somewhat vague term "critical thinking skills" and how the department can help facilitate their development. A final recommendation would be to go into current required classes and ask current students what they are most concerned about as sociology majors and how the department can help. Sociology majors do 
not expect or demand high salaries or high levels of prestige. Most have chosen sociology because of a true interest in the subject and an alignment with the sociological perspective. The department can only be strengthened internally and externally by a better understanding of its majors and a sincere effort to better meet their needs. 
<blank> 


\section{SELECTEd BibliogRAPHY}

Baker, Paul and William C. Rau. 1990. "The Cultural Contradictions of Teaching Sociology" in Sociology in America. (Herbert Gans, ed.) Newbury Park, CA. Sage Publications.

Bassis, Michael. 1986. "The Quality of Undergraduate Education: Toward an Agenda for Inquiry and Action." Teaching Sociology. 14:1-10.

Becker, Howard S. and William C. Rau. 1992. "Sociology in the 1990s." Society 31(1): 70-74.

Berger, Peter L., 1971. "Sociology and Freedom." The American Sociologist, 6(February): 1-5.

Braxton, John M., Nick Vesper and Don Hossler. 1995. "Expectations for College and Student Persistence." Research in Higher Education 36(5): 595-612.

Bruton, Brent T. and Sue R. Crull. 1985. "A Systems Approach to Individualizing Mass Sections of Introductory Sociology." Teaching Sociology 13(1): 34-45.

Collins, Sharon K., et al. 1990. "The Contributions of Sociology to the Liberally Education Person." Teaching Sociology (October): 494-498.

Conklin, George H. and Isaac A. Robinson. 1985. "Introductory Sociology's Role as a Service Course." Teaching Sociology 13(1):4660.

Cover, Dan. 1995. "Teaching Sociology as a Science: A Laboratory Reinforcement of the Sociological Heritage." Teaching Sociology 23 (July): 226-233.

Devlin, J. Stuart and Robin T. Peterson. 1994. "Student Perceptions of Entry-Level Employment Goals: An International Comparison." Journal of Education for Business (Jan/Feb): 154-158.

Freeman, Howard E. and Peter H. Rossi. 1984. "Furthering the Applied Side of Sociology." American Sociological Review 49(August): 571580 . 
Guppy, Neal and A. Bruce Arai. 1994. "Teaching Sociology: Comparing Undergraduate Curricula in the United States and in English Canada." Teaching sociology 22(July): 217-230.

Hartman, David E. and Sandra L. Schmidt. 1995. "Understanding Student/Alumni Satisfaction from a Consumer's Perspective" The Effects of Institutional Performance and Program Outcomes." Research in Higher Education 36(2):197-217.

Hobbs, Tom R. 1993. "In Defense of Sociology: A Note." Sociological Inquiry 63(4): 471-477.

Howery, Carla B. 1985. "From the Special Issue Editor: Playing the Ends Against the Middle." Teaching Sociology 13(1):4-11.

Huber, Joan, 1995. "Institutional Perspectives on Sociology." American Journal of Sociology 101(1): 194-216.

Jacobs, Jerry A. 1995. "Gender and Academic Specialties: Trends among Recipients of College Degrees in the 1980s." Sociology of Education 68(April): 81-98.

Keith, Bruce and Helen A. Moore. 1995. "Training Sociologists: An Assessment of Professional Socialization and the Emergence of Career Aspirations." Teaching Sociology 23(July): 199-214.

Knox, William E., Paul Lindsay and Mary N. Kolb. 1992. 1992. "Higher Education, College Characteristics and Student Experiences." Journal of Higher Education 63(3): 303-328.

Kremer, John F. and Robert G. Bringle. 1990. "The Effects of Intensive Research Experience on the Careers of Talented Undergraduates." Journal of Research and Development in Education 24(1):1-5.

Kressel, Neil J. 1991. "Job and Degree Satisfaction Among Social Science Graduates." Teaching of Psychology 17(4): 222-227.

Lewis-Beck, Michael S. 1980. Applied Regression: An Introduction. Sage Publications, Newbury Park, California.

McGee, Reece, Charlotte A. Vaughan, and Paul J. Baker. 1985. "Introductory Discussion for a Discipline in Decline." Teaching Sociology 13(1): 12-33.

McGovern, Thomas V. and Brenda K. Hawks. 1987. "The Varieties of Undergraduate Experience." Teaching of Psychology 13(4): 174-181. 
Paap, Warren R. and J. Daniel McMilliam. 1990. "The BA in Sociology: Who Gets What out of It?" Teaching Sociology. 18:20-25.

Pike, Gary R. 1994. "The Relationship Between Alumni Satisfaction and Work Experiences." Research in Higher Education 35(1): 105-123.

Porkess, Roger. 1991. The Harper Collins Dictionary of Statistics. Harper Collins Publishers: New York, New York.

Rau, William. 1992. "The Good Sociology Departments: Will We Ever Find Them? Will We Even Try?" Teaching Sociology 20(April) 165-170.

Rau, William, and Paul J. Baker. 1989. "The Organized Contradictions of Academe: Barriers facing the Next Academic Revolution." Teaching Sociology 17(April): 161-175.

Rifenbary, Deborah. 1995. "Reentering the Academy: The Voices of Returning Women Students." Initiatives 56(4): 1-10.

Roberts, Keith A. 1986. "Sociology in the General Education Curriculum: A Cognitive Structuralist Perspective." Teaching Sociology 14(October):207-216.

Rossi, Peter H., James D. Wright, and Andy B. Anderson. 1983. Handbook of Survey Research. Academic Press, New York, New York.

Ruggiero, Josephine A. and Louise C. Weston. 1986. "Marketing the B.A. Sociologist: Implications from Research on Graduates, Employers, and Sociology Departments." Teaching Sociology. 14(October): 224233.

Schaefer, Richard and Robert Lamm (eds.). 1995. Sociology, 5th edition. New York: McGraw Hill.

Sharkey, Stephen R. 1990. "An Approach To Organizing The Undergraduate Social Science Major Around Learning Outcomes." Teaching Sociology 18(October): 472-481.

Smith, Christopher B. 1990. "Sociology and The Liberal Arts: A Sociohistorical Integration." Teaching Sociology 18(October):482-487.

Szafran, Robert F. 1986. "What do Introductory Sociology Students know and When do they Know it? The Results of Pretesting Students." Teaching Sociology 14(October): 217-223. 
Tozer, Steven, Paul C. Violas, and Guy B. Sense. 1993. School and Society: Educational Practice as Social Expression. McGraw-Hill, Inc., New York, New York.

Turner, Stephen P. and Jonathan H. Turner. 1990. The Impossible Science: An Institutional Analysis of American Sociology. Newbury Park, California: Safe Publications, Inc.

National Center for Education Statistics. 1995. 1995 Digest of Education Statistics. United States Department of Education.

Vaugh, Ted R., Gideon Sjoberg, and Larry T. Reynolds. 1993. A Critique of Contemporary Sociology. New York: General Hall, Inc.

Velasco, Steven C., Susan E. Stockdale and David J. Scrams. 1992. "Sociology and Other Social Sciences: California State University Alumni Ratings of the B.A. Degree for Development of Employment Skills." Teaching Sociology 20(January): 60-70.

Wagenaar, Theodore C. 1993. "Study in Depth: Sociology Versus Other Disciplines." Teaching Sociology 21(October):352-362.

Watts, W. David and Ann Marie Ellis. 1989. "Assessing Sociology Educational Outcomes: Occupational Status and Mobility of Graduates." Teaching Sociology. 17:297-306.

White, Charles R. (Chair). 1993. General Education Working Group Report and Recommendations. Portland State University. October, 1993. 


\section{CURRENT SOCIOLOGY STUDENT SURVEY}

Your opinions are very important to us, so please try to consider and answer each question carefully. PART I. YOUR COLLEGE EXPERIENCE

1. In this section, we would like to find out why you majored in sociology. How important were each of the following in your decision to major in sociology? Please use a scale from 1 to 5 with " 1 " meaning Extremely Important and "5" meaning Not Important At All.
a. Specific instructor(s) at PSU (Please name: )
b. The content of a specific class(es) at PSU (Please name:
$\begin{array}{lllll}1 & 2 & 3 & 4 & 5\end{array}$
c. Sociology only required one term of statistics
$\begin{array}{lllll}1 & 2 & 3 & 4 & 5\end{array}$
$\begin{array}{lllll}1 & 2 & 3 & 4 & 5\end{array}$
$\begin{array}{lllll}1 & 2 & 3 & 4 & 5\end{array}$
$\begin{array}{lllll}1 & 2 & 3 & 4 & 5\end{array}$
$\begin{array}{lllll}1 & 2 & 3 & 4 & 5\end{array}$
d. Sociology classes were easy for me
e. I liked the sociological perspective
f. I knew someone who was majoring in sociology
g. I thought a degree in sociology would make me more
h. I enjoyed my first sociology class
$\begin{array}{lllll}1 & 2 & 3 & 4 & 5\end{array}$
i. I was impressed with the quality of classroom instruction
$\begin{array}{lllll}1 & 2 & 3 & 4 & 5\end{array}$
j. I wanted to work in a helping profession
$\begin{array}{lllll}1 & 2 & 3 & 4 & 5\end{array}$
k. Sociology classes fit into my schedule
$\begin{array}{lllll}1 & 2 & 3 & 4 & 5\end{array}$

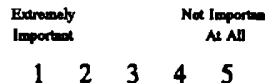

2. Choosing from the list above, which items would you rank as the most important in your decision to major in sociology. Please write the letter of the items in the space provided below.

Most important

Second

Third

3. Please indicate your level of agreement with the following statements by checking the appropriate box.

a. As a result of studying sociology, I understand society better than most people. [ ] Strongly agree [ ] Agree [] Disagree [ ] Strongly disagree

b. I feel comfortable approaching my sociology professors outside of class.

I] Strongly agree [] Agree [] Disagree [ ] Strongly disagree

c. Courses at PSU should put more emphasis on applied skills.

[ ] Strongly agree [ ] Agree [ ] Disagree [ ] Strongly disagree

d. My sociology major consists of a collection of more or less unrelated courses. [] Strongly agree [] Agree [] Disagree [] Strongly disagree

e. So far, I feel that studying sociology is a good investment of my time and money. [ ] Strongly agree [ ] Agree [ ] Disagree [ ] Strongly disagree

f. I am satisfied with the academic advising offered by the sociology department. [ ] Strongly agree [] Agree [ ] Disagree [ ] Strongly disagree 


\section{Appendix A}

Surveys Mailed to Alumni and Current Students

g. I am glad that I decided to major in sociology.

[] Strongly agree [ ] Agree [ ] Disagree [ ] Strongly disagree

h. Overall, I am satisfied with the content of my sociology classes.

[] Strongly agree [ ] Agree [ ] Disagree [ ] Strongly disagree

i. I would recommend the sociology undergraduate program at PSU to others.

[ ] Strongly agree [] Agree [] Disagree [ ] Strongly disagree

4. The purpose of this section is to find out what types of skills and experiences students hope to gain from their studies in sociology. If you were to design an undergraduate program to best suit your needs, how much importance would you place on the following areas? Please use a scale from 1 to 5 with " 1 " meaning Extremely Important and " 5 " meaning Not Important At All.

a. Experience with Computers

b. Writing skills

c. Studying topics such as groups, urbanization, and formal organizations

d. Department coordinated internships

e. Experience conducting survey research

f. Classical sociological theory (e.g., Marx, Weber)

g. The development of critical thinking skills

h. Learning to read and interpret statistical data

i. Contemporary sociological theories (e.g., symbolic interaction, feminist theory)

j. Experience conducting case studies

k. Learning interview skills

1. Studying topics such as stratification, inequality, and social class

m. Preparation for graduate school

n. Learning what kinds of jobs are available to sociology graduates

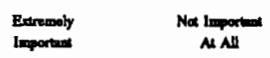

$\begin{array}{lllll}1 & 2 & 3 & 4 & 5\end{array}$

$\begin{array}{lllll}1 & 2 & 3 & 4 & 5\end{array}$

$\begin{array}{lllll}1 & 2 & 3 & 4 & 5\end{array}$

$\begin{array}{lllll}1 & 2 & 3 & 4 & 5\end{array}$

$\begin{array}{lllll}1 & 2 & 3 & 4 & 5\end{array}$

$1 \quad 2 \quad 3 \quad 4 \quad 5$

$\begin{array}{lllll}1 & 2 & 3 & 4 & 5\end{array}$

$\begin{array}{lllll}1 & 2 & 3 & 4 & 5\end{array}$

$\begin{array}{lllll}1 & 2 & 3 & 4 & 5\end{array}$

$\begin{array}{lllll}1 & 2 & 3 & 4 & 5\end{array}$

$\begin{array}{lllll}1 & 2 & 3 & 4 & 5\end{array}$

$\begin{array}{lllll}1 & 2 & 3 & 4 & 5\end{array}$

$\begin{array}{lllll}1 & 2 & 3 & 4 & 5\end{array}$

$123 \quad 3 \quad 4 \quad 5$

5. Choosing from the list above, which three items should receive the most emphasis? Please write the letter of the items in the space provided below.

Most important

Second

Third

6. People have many different reasons for going to college. For the following question, we would like you to consider only the four alternatives listed below and rank them using a scale from " 1 " to " 4 ," with " 1 " indicating Most Important, and "4" indicating Least Important:

What were your reasons for going to college?

Rank

To prepare me for a good job

To gain personal knowledge

It seemed like the best thing to do at the time

My parents wanted me to go 
7. Please describe what you would like to accomplish in the six months following your graduation:

\section{PART II. QUESTIONS ABOUT YOURSELF}

May we remind you that all answers are confidential and will be used only in combination with those of other respondents to form a composite picture of PSU sociology majors.

1. What is your sex?
[ ] Male
[] Female

2. What is your age?

3. What is your current class standing?
[ ] Freshman
[ ] Senior
[] Sophomore
[] Post baccalaureate
[ ] Junior

4. What is your usual enrollment status during the academic year? [ ] Full time [] Part time

5. Did you transfer to PSU from another institution?

[ ] Yes, from a community college
[] Yes, from a four year school
[] No, 1 started at PSU

6. When did you decide to major in sociology?

[] During high school

[] During my freshman or sophomore year at college

[ ] During my junior or senior year at college

[ ] I don't remember

[] Other (Please specify:

7. What is the highest level of education your mother completed?
[1] Less than high school
[ ] Bachelor's degree
[] High school
[ ] Graduate degree
[ ] Vocational/Technical Training
[] Not applicable
[] Some college
[ ] Don't know
[] Associate's degree

8. What is the highest level of education your father completed?
[ ] Less than high school
[] Bachelor's degree
[ ] High school
[ ] Graduate degree
[] Vocational/Technical Training
[] Not applicable
[] Some college
[] Don't know
[] Associate's degree

9. What is your employment situation during a typical quarter?
[ ] Not employed
I] Employed less than 10 hours per week
[ ] Employed 10 to 19 hours per week
[] Employed 20 to 29 hours per week
[ ] Employed 30 or more hours per week 


\section{Appendix A}

Surveys Mailed to Alumni and Current Students

10. Please indicate your current or most recent job title:

11. Please check the response which is closest to your total personal income, before taxes, in 1993.
[ ] Less than $\$ 5,000$
[ ] $\$ 15,000$ to $\$ 24,999$
[ ] $\$ 5,000$ to $\$ 9,999$
[ ] $\$ 25,000$ to $\$ 34,999$
[] $\$ 10,000$ to $\$ 14,999$
[] $\$ 35,000$ or over

12. Do other people (e.g., spouse, family) contribute to your living expenses while you attend college? [ ] No

[] Yes (If yes, who?

13. What is the major source of your tuition payments while attending PSU? (Please check only ONE category)
[] Scholarships
[1 Employer
[] Student loans
[] Family loans or gifts
[] Personal loans
[] Your own savings
[] Grants
[] Other (Please specify:

Please use the space provided below to suggest any improvements you feel could be made to the sociology undergraduate program at PSU.

Thank you for your cooperation in completing this survey.

Please return the survey as soon as possible in the enclosed postage paid envelope. 


\section{SOCIOLOGY ALUMNI SURVEY}

Your opinions are very important to us, so please try to consider and answer each question carefully.

\section{PART I. YOUR COLLEGE EXPERIENCE}

1. The purpose of this section is to ask your help in improving the undergraduate sociology program at PSU. Based on your experiences since graduation, how much importance would you place on the following areas? Please use a scale from 1 to 5 with "1" meaning Extremely Important and "5" meaning Not Important At All.
a. Experience with Computers
b. Writing skills
$\begin{array}{lllll}1 & 2 & 3 & 4 & 5\end{array}$
c. Studying topics such as groups, urbanization, and formal organizations
$\begin{array}{lllll}1 & 2 & 3 & 4 & 5\end{array}$
$\begin{array}{lllll}1 & 2 & 3 & 4 & 5\end{array}$
d. Department coordinated internships
$\begin{array}{lllll}1 & 2 & 3 & 4 & 5\end{array}$
e. Experience conducting survey research

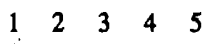
f. Classical sociological theory (e.g., Marx,
1. $2 \begin{array}{lllll} & 3 & 4 & 5\end{array}$ Weber)
g. The development of critical thinking skills
$\begin{array}{lllll}1 & 2 & 3 & 4 & 5\end{array}$
h. Learning to read and interpret statistical data
$\begin{array}{lllll}1 & 2 & 3 & 4 & 5\end{array}$
i. Contemporary sociological theories (e.g.,
$\begin{array}{lllll}1 & 2 & 3 & 4 & 5\end{array}$ symbolic interaction, feminist theory)
j. Experience conducting case studies
$\begin{array}{lllll}1 & 2 & 3 & 4 & 5\end{array}$
k. Learning interview skills
$\begin{array}{lllll}1 & 2 & 3 & 4 & 5\end{array}$
1. Studying topics such as stratification,
$\begin{array}{lllll}1 & 2 & 3 & 4 & 5\end{array}$ inequality, and social class
m. Preparation for graduate school
$\begin{array}{lllll}1 & 2 & 3 & 4 & 5\end{array}$
n. Learning what kinds of jobs are available to
$\begin{array}{lllll}1 & 2 & 3 & 4 & 5\end{array}$

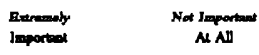

2. Choosing from the list above, which three items should receive the most emphasis? Please write the letter of the items in the space provided below.
Most important
Second
Third

3. Please indicate your level of agreement with the following statements by checking the appropriate box.

a. As a result of studying sociology, I understand society better than most people. [ ] Strongly agree [ ] Agree [] Disagree [ ] Strongly disagree

b. I felt comfortable approaching my sociology professors outside of class.

[ ] Strongly agree [] Agree [] Disagree [ ] Strongly disagree

c. Courses at PSU should put more emphasis on applied skills.

[ ] Strongly agree [] Agree [] Disagree [] Strongly disagree

d. My sociology major consisted of a collection of more or less unrelated courses.

[ ] Strongly agree [ ] Agree [] Disagree [ ] Strongly disagree

e. My undergraduate sociology degree was a good investment of my time and money. [] Strongly agree [] Agree [] Disagree [] Strongly disagree 
f. I received sufficient academic advising from the sociology department. [ ] Strongly agree [] Agree [] Disagree [ ] Strongly disagree

g. I am glad that I majored in sociology.

[ ] Strongly agree [ ] Agree [ ] Disagree [] Strongly disagree

h. Overall, I felt satisfied with the content of the sociology classes at PSU.

[ ] Strongly agree [ ] Agree [ ] Disagree [ ] Strongly disagree

i. I would recommend the sociology undergraduate program at PSU to others.

[ ] Strongly agree [ ] Agree [] Disagree [] Strongly disagree

4. In the space provided below, please list those courses and professors, both within the sociology department and from other departments, which have been occupationally and personally valuable to you since graduation.

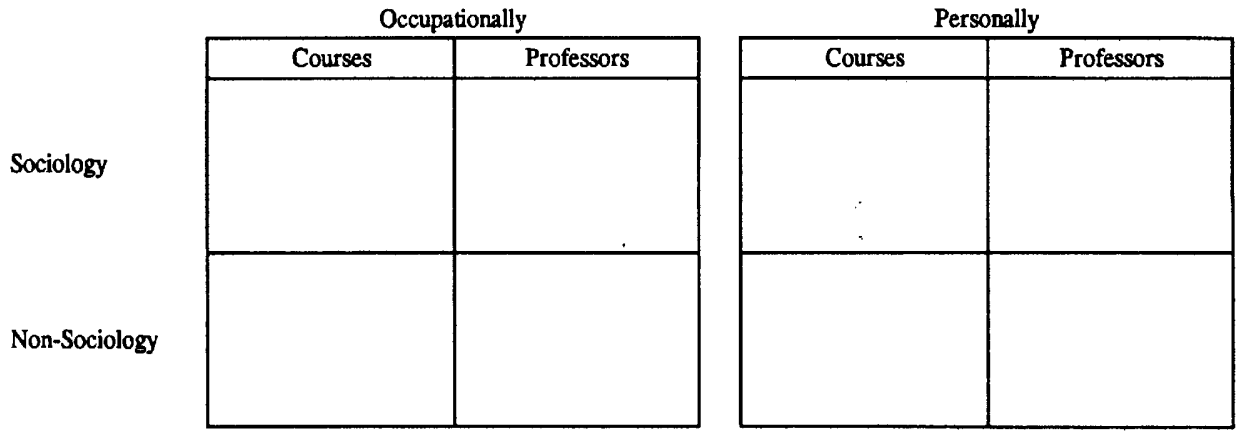

\section{PART II. YOUR OCCUPATIONAL SITUATION}

1. What is your current employment situation? Check all that apply.

[ ] Employed full time ( 30 or more hours per week)

[] Employed full time, but seeking other employment

[ ] Employed part time (fewer than 30 hours a week)

[ ] Employed part time, but seeking full time employment

[ ] Unemployed and seeking employment

[ ] Unemployed and not seeling employment

[] Other (please specify: )

IF YOU ARE NOT CURRENTLY EMPLOYED FULL OR PART TIME, PLEASE SKIP TO QUESTION 6.

2. Please indicate your current job title:

3. Does your current job require a college degree?
[] Yes
[] No

4. Do you consider yourself under-employed relative to your education?
[] Yes
[ ] No

5. Please indicate your level of agreement with the statements listed below by checking the appropriate box.

a. My sociology undergraduate degree is very helpful in my present job.

[] Strongly agree [] Agree [] Disagree [] Strongly disagree

b. It was difficult for me to find my current job.

[ ] Strongly agree [] Agree [ ] Disagree [] Strongly disagree 
c. I am satisfied with the income from my job.

[ ] Strongly agree [ ] Agree [] Disagree [ ] Strongly disagree

d. I could just as easily perform my current job without an undergraduate degree in sociology.

[ ] Strongly agree [ ] Agree [ ] Disagree [ ] Strongly disagree

e. My current job is consistent with my career choice.

[ ] Strongly agree [] Agree [] Disagree [ ] Strongly disagree

f. Other than a paycheck, my current job has little meaning to me.

[ ] Strongly agree [] Agree [ ] Disagree [1] Strongly disagree

g. Most days I am enthusiastic about my work.

[] Strongly agree [ ] Agree [] Disagree [ ] Strongly disagree

h. I am satisfied with my job for the time being.

[] Strongly agree [ ] Agree [] Disagree [] Strongly disagree

6. To what extent does your current or most recent job involve the following tasks or activities? Please use a scale from 1 to 5 with "1" meaning To a Great Extent and "5" meaning Not At All.

$\begin{array}{ll}\text { a. } & \text { Supervising other employees } \\ \text { b. Library research } \\ \text { c. Counseling } \\ \text { d. Teaching/training } \\ \text { e. Using a language other than English } \\ \text { f. Taking instructions from a supervisor } \\ \text { g. Reading and interpreting statistical data } \\ \text { h. Preparing, compiling, organizing numerical data } \\ \text { i. Working with computers } \\ \text { j. Writing grant proposals } \\ \text { k. Writing memos, reports, case histories, etc. } \\ \text { l. } \quad \text { Selling products or services } \\ \text { m. } \quad \text { Clerical tasks } \\ \text { n. } \quad \text { Other (Specify: }\end{array}$

\begin{tabular}{|c|c|c|c|c|}
\hline 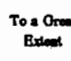 & & & & $\begin{array}{c}N_{\alpha A A} A t \\
A_{I I}\end{array}$ \\
\hline 1 & 2 & 3 & 4 & 5 \\
\hline 1 & 2 & 3 & 4 & 5 \\
\hline 1 & 2 & 3 & 4 & 5 \\
\hline 1 & 2 & 3 & 4 & 5 \\
\hline 1 & 2 & 3 & 4 & 5 \\
\hline 1 & 2 & 3 & 4 & 5 \\
\hline 1 & 2 & 3 & 4 & 5 \\
\hline 1 & 2 & 3 & 4 & 5 \\
\hline 1 & 2 & 3 & 4 & 5 \\
\hline 1 & 2 & 3 & 4 & 5 \\
\hline 1 & 2 & 3 & 4 & 5 \\
\hline 1 & 2 & 3 & 4 & 5 \\
\hline 1 & 2 & 3 & 4 & 5 \\
\hline 1 & 2 & 3 & 4 & 5 \\
\hline
\end{tabular}

\section{PART III. QUESTIONS ABOUT YOURSELF}

May we remind you that all answers are confidential and will be used only in combination with those of other respondents to form a composite picture of PSU sociology alumni.

1. What is your sex? [ ] Male [ ] Female

2. What is your age?

3. What is the highest level of education your mother completed?
[] Less than high school
[] Bachelor's degree
[] High school
[] Graduate degree
[] Vocational/Technical Training
[] Not applicable
[] Some college
[ ] Don't know
[] Associate's degree 


\section{Appendix A}

\section{Surveys Mailed to Alumni and Current Students}

4. What is the highest level of education your father completed?
[ ] Less than high school
[] Bachelor's degree
[] High school
[ ] Graduate degree
[ ] Vocational/Technical Training
[] Not applicable
[ ] Some college
[] Don't know
[] Associate's degree

5. Please check the response which is closest to your total personal income, before taxes, in 1993.
I ] Less than $\$ 5,000$
[ ] $\$ 5,000$ เo $\$ 9,999$
[] ] $\$ 25,000$ to $\$ 34,999$
[] $\$ 10,000$ to $\$ 14,999$
[] $\$ 35,000$ 10 $\$ 49,999$
[ ] $\$ 15,000$ to $\$ 24,999$
[] $\$ 50,000$ to $\$ 74,999$
[] $\$ 75,000$ or over

6. What was the major source of your tuition payments while attending PSU? (Check only ONE category)
[ ] Scholarships
[ ] Employer
[] Student loans
[ ] Family loans or gifts
[] Personal loans
[] Your own savings
[ ] Grants
[ ] Other (Please specify: )

7. What is the highest level of education you have obtained to date?

(Check only ONE category)

[ ] Graduated from four year college [ ] Master's degree (Which field?

[] Post-graduate sudy without degree

8. Do your future plans include more education?
[ ] Yes (What field?
[] No

9. What year did you receive your undergraduate degree?

10. In the space provided below, please indicate why you decided to major in sociology:

11. Please use the space below to suggest any improvements that could be made to the sociology undergraduate program at PSU. If you have additional comments, please include them on a separate sheet of paper and return with the survey. 


\section{Appendix B}

Plans of Current Students Six Months After Graduation

CURRENT STUDENTS WERE ASKED: PLEASE DESCRIBE WHAT YOU WOULD LIKE TO ACCOMPLISH IN THE SIX MONTHS FOLLOWING YOUR GRADUATION. THEIR RESPONSES HAVE BEEN GROUPED FOR THEMES (EMPLOYMENT, GRADUATE SCHOOL, BOTH).

\section{FIND EMPLOYMENT}

- A job in a social science field - nice if it would be over $\$ 5.50$ an hour.

- Get a job in the field of juvenile corrections and counseling and earn an income greater than my current salary.

- To have some idea of which direction I will go from there with some possibility of a job lead.

- To find a job that is flexible as to allow me to spend time with my preschooler and volunteer in her school.

- A good job.

- Finding meaningful employment which utilizes all I've learned.

- I'd like to investigate what types of jobs might be possible for me to obtain with a degree in sociology - and even possibly become employed in one of these jobs. I'd also like to relax.

- I am planning to secure a full time position at my current job so I will be able to purchase a home. Once my home is secure, I would like to continue my education with graduate school.

- I would like to search out and find a job where my financial needs are satisfied along with doing something that makes a difference in other people's lives.

- I want to use and challenge my skills in a job that rewards me intrinsically and monetarily (I want to be happy and at the same time, pay back my loans).

- I would be happy with obtaining any kind of job in sociology field to gain experience - and then hopefully find my niche and begin a career in a specialized field. 


\section{Appendix B \\ Plans of Current Students Six Months After Graduation}

- I graduated over one year ago, but my goal was to get a job and gain experience.

- Complete a vigorous job search and land a good job in the human services field.

- Get a decent paying job, probably not in social work, hope to by working abroad in July.

- Start up own business in counseling career advising/employment.

- To be employed.

- Get a good job.

- Get a job and make some money. Figure out if I should go to graduate school or not.

- Full time employment overseas.

- During the last two and a half months I have put in dozens of government agency application to no avail. I sincerely hope to seek a job position that gives me income above what I was making three years ago, before I went back to school, to PSU for a bachelors.

- Find what type of career I would like to pursue.

- I would like to have a job that I enjoy and that I can make a descent income from.

- I would eventually like to be associated with a professional counseling group (e.g., drug alcohol, marriage, stress management, counseling, etc.)

- Begin a job in a social work type setting - that is actually my first area of interest.

- I would like to have a number of people, employers considering me for jobs in social work, hopefully something involving social change.

- To heal from the experience and try to find some kind of work that can be loved enough.

- To get a job that I can look forward to performing most days.

- Arrive in Japan and begin teaching English through the JET program at PSU.

- Find a full-time "permanent" job related to community affairs. 


\section{Appendix B}

Plans of Current Students Six Months After Graduation

- Move away from Oregon - to a warmer climate and get a job in advertising.

- Travel, introspection, get a job.

- Find a job at a golf course.

- Find employment in an institution which would provide an atmosphere to encourage less fortunate individuals an opportunity to gain self-esteem in themselves.

- Find a job that is relative to my field of interest.

- Get a job that will turn into a career for me.

- Find a job in which my degree would enable me to help women in abusive situations.

- I plan to take a little time off, but then I would like to volunteer some time to local organization that are involved with children. Possibly - look into job openings with the state and government.

- I would like to get a full-time job in an entry level position, work for two years to repay loans, and then proceed to graduate school.

- Get a job or career in my field of studies.

\section{GRADUATE SCHOOL}

- Get accepted to graduate school.

- I intend to go to graduate school after receiving my B.S. I hope to earn my MSW.

- Successful completion of my first term of graduate school.

- I plan to go on to graduate school fall term.

- Get into graduate school.

- If possible I want to continue my education to get a MSW degree.

- Go to graduate school. 


\section{Appendix B \\ Plans of Current Students Six Months After Graduation}

- Acceptance into the graduate school of social work. Take a break for foreign travel (1-2 months).

- Entering the occupational therapy school in Washington (U of W). My sociology degree will help and prepare me for working in this field.

- Find a part time job until my son graduates from high school and then possibly attend graduate school in Education or social work.

- In special education program at PSU.

- Travel-prepare for graduate school-special education.

- I enrolled in graduate studies in social work. I hope to use the research knowledge, theory, and understanding of social structure in this work.

- Acceptance to a graduate program.

\section{BOTH}

- I plan on working in Alaska to earn money so I can continue with a MSW degree.

- A short rest and find work that will support graduate school.

- Work experience in the field and preparation for graduate school.

- To find a viable and meaningful genre to gain experience, through being an employee or volunteer while remaining in school to gain my graduate degree Administration of Justice or Social Work.

- Get a job and begin working on my Master's in Education.

- Prepare for graduate school while making money to pay for it.

- Locate employment and prepare for graduate school outside the sociology field, perhaps studying skills for applicable to the business world. 


\section{Appendix C \\ Job Titles Listed By Alumni}

Academic Advisor

Accounting Specialist

Accounting Technician

Accounts Receivable Manager

Administrative Assistant (4)

Administrator

Adoption Birth Parent Clinician

Adoption Specialist, CSD

Advertising Coordinator

After Hours Coordinator

Agent with D.A.'s office

Apartment Manger

Area Director, Non-Profit

Assistant Manager Retail

Assistant Planner

Assistant Superintendent of School District

Assistant to Circulation Director (Newspaper)

Assistant to City Commissioner

Assistant to Mental Health Director

Associate Director (Center for Health System Studies)

Associate General Secretary

Associate Instructor

Attorney/Trust Officer

Bank Teller

Bookkeeper Assistant in Health Clinic

Branch Manager Social Service Agency

Business Owner

Business Systems Analyst

Businesswoman

California Technical Sales Representative

Carpet Installer

Case Management (6)

CEO

Chief Judge

Chief of Police (Lake Oswego)

Chief Planner, Columbia County

Child Specialist (3)

Children's Activity Coordinator

City Planner (2)

Clergy

Clerk (2)

Clinical Case Manager

Clinical/Medical Social Worker

Commercial Real Estate Sales

Community College Instructor 


\section{Appendix C}

Job Titles Listed By Alumni

Community Coordinator Hood River Behavioral Research

Community Support Staff (DD Group Home)

Comptroller

Computer Operator

Computer Technician

Consultant-Human Resources

Contractor

Contractor-Research

Cook

Counselor (6)

Courier Driver

Courtroom Clerk

Customer Programs Coordinator

Customer Service (3)

Deputy Ambassador, U.S. Embassy (career diplomat)

Director of Eligibility Programs

Disaster Management Consulting

District Account Manager (2)

Diversity Trainer

EAP Counselor for USPS

Early Childhood Education Coordinator

Editor

Educational Assistant

Elementary School Teacher (2)

Eligibility Specialist

Employment and Training Specialist

English Language Teacher

ESL Teacher

Executive Assistant

Executive Director (3)

Executive Secretary

Executive Vice President - Small Business Owner

Export Coordinator

FBI-CIA Coordinator on Location

Fiscal Coordinator

Full time Mom

General Manager

Grocery Clerk

Guest Service Manager

Head Start Teacher/Home Visitor

High School and College Program Director

High School Principal

Homemaker

Housing Coordinator Manager

Human Resource Specialist 


\section{Appendix C}

Job Titles Listed By Alumni

Human Resources Assistant

Human Services Assistant II

Information Desk Supervisor

Instructor - Sociology

Insurance Agent

Job Service Representative

Journalist

Juvenile Rehabilitation Counselor

L.P.N.

Lawyer

Legal Assistant

Legal Secretary

Letter Carrier USPS

Licensed Clinical Social Worker

Licensed Real Estate Assistant

Loan Quality Control Office

Lobbyist/Research and Education Director, Oregon AFL-CIO

Lumber Sales Manager

Magazine Publisher

Manager (7)

Manager, Information Services

Manager, Optical Occupations

Manager, Order Center

Managing Principal

Manufacture Sales Representative

Marketing Research Intern

Martial Arts Instructor

Medical Social Worker (3)

Member Service Representative

Mental health Therapist (2)

Meter Reader

Multnomah County Supervisor

News Corespondent

Nursing Home Administrator

Office Manager (3)

Operations Manger

Outreach Assistant

Own Sales Company

Owner

Owner - Flowers and Gifts

Owner - Home Daycare

Owner of Insurance Agency

Owner, Carpet Classics

Owner/hair stylist

Owner/Operator Creative Home Preschool 
Parole Agent

Pastor

Patient Services Staff

Personal Health Advisor

Personnel Generalist

Phone Operator

Physician

Physician Assistant

Pilot

Planner (2)

Policy Analyst

Policy Service Representative

Post Doctoral Fellow

President

President/owner

Principle Executive Manger

Professor of Criminology, University of Maryland

Program Administrator

Program Liaison to the Disabled Workers Project

Program Manager (2)

Program Therapist/Utilization Review

Project Archivist

Project Leader - Information Systems

Project Manger

Public Education Director

Public Relations Assistant

Qualified Mental Health Associate

Quality Assurance Manger

Quality Systems Conformance Technician

Real Estate (3)

Regional Manager

Regional Transportation Planner

Registered Nurse

Research Assistant (4)

Residential Advocate

Residential Case Worker

Residential Group Home Client Supervisor

Residential Life Counselor

Retail Store Owner

Retired (5)

Risk Intervention Case Manager

$\mathrm{RN}$, Case Management

Rural Letter Carrier, USPS

Sales \& Receiving for bookstore

Sales Director 


\section{Appendix C}

Job Titles Listed By Alumni

Sales Manager

Sales Representative (4)

School Principal

Self-employed

Self-employed Carpet Cleaner

Senior Advocate

Senior Analyst (Information Services Department)

Senior MIS Analyst

Senior Regional Planning

Senior Technical Writer

Social Service Specialist

Social Service Specialist - Caseworker for Children Services Division

Social Service Supervisor

Social Services Specialist - CSD

Social Worker (3)

Social-Service Director

Software Engineer

Staff Accountant

Staff Agency Director

Staff Assistant

Student Services Coordinator

Substitute Special Education and Rating Teacher

Supervisor

Supervisor in Local Child Abuse Evaluation Project

Supervisor of Case Manager

Supervisory Computer Analyst

Support Clerk

Surgical Nurse RN

Teacher (3)

Teacher/Counselor

Teaching Assistant (2)

Technical Information Officer

Technical Writing/Illustrating

Television News Producer

Trade Show Coordinator

Trial Assistant - Public Defender's Office

Trust Officer

Unit Director (Administrative State Institution)

Utility Worker

V.P. and Manger of Human Resources

Vault Supervisor/Officer

Vocational Supervisor/Counselor

Volunteer Coordinator

Waitress

Waitress, Embassy Suites Hotel 


\section{Appendix D}

Alumni Responses Regarding Why They Decided To Major In Sociology

- I enjoyed the subject and classes. The department head was sincere and showed interest in helping with advising needs. Professors were interesting and knowledgeable.

- Vague interest in subject matter on entering college. Recommended by older students I knew.

- I wanted to see the world! It didn't pay!

- Intended to pursue career in social services.

- Easiest.

- I wanted to be in a "helping" profession where I'd be in a position to help downtrodden people. I was idealistic.

- I was already working as a paramedic, had thought about a business degree, took classes for two years and felt like I was getting too far away from the human touch that I cherished.

- Seemed to provide the broadest "stepping off" point to continue with urban studies; also my personal interest.

- It thought that was what I needed to be a counselor. Would have done better in psychology or BSW.

- Interest in understanding and attempting to solve the problem of poverty. Interest in organizations developed.

- I changed my major every term the first two years of undergraduate school. I liked the sociology classes the best so I majored in it.

- Double major - chemistry/sociology.

- I am interested in the behavior of people in groups. I had a sincere desire to help people. The sociology department, at that time had a reputation as an easy, "push over" degree program. You could graduate with very little effort. At that time, a good GPA was all employers were interested in - even if it was a degree in underwater basket weaving.

- To explore interpersonal, intrapersonal relationships. 


\section{Appendix D}

Alumni Responses Regarding Why They Decided To Major In Sociology

- I like the balance of a double major in sociology and psychology with my masters in social work. The focus of the person in their culture with the practical application of social work skills in counseling has given me exactly the balanced perspective I wanted and needed. I hope my clients agree.

- At the time, I waned to be a juvenile counselor.

- An interest in how society as a whole affects the individual person.

- I wanted to learn more about the ways and reasons people interact with each other.

- It provided a good, broad base of perspective on human issues. Group dynamics, etc., which built on what I already knew in a general way about life, groups, and people.

- I took a lot of sociology courses at my previous college, and I wanted to "wrap it all up".

- I planned to get a degree in forestry, but did not have the math/science skills needed, so I settled on sociology because I couldn't find a criminology program in the state (certification in Administration of Criminal Justice was as close as I got to criminology).

- Organizational theory combined with statistical analysis and survey methodology. Lee Haggerty's interest in urban/regional planning; his sponsoring of off campus intern credit with METRO. Sociology combined well with urban and regional economics, and economics in general.

- Interested in what makes people tick.

- Found study interesting and at the time was planning to go on to get graduate degree advisor recommended BS degree be a broad field of study such as sociology or psychology, etc.

- It interested me.

- It chose me.

- Vital to me to be in a helping profession.

- The extremely high academic expectations of Drs. Davis, Glazer, and Brenner with fascinating content to learn were a challenge. 


\section{Appendix D}

Alumni Responses Regarding Why They Decided To Major In Sociology

- It was by accident. My first major was psychology and I supplemented with speech and sociology classes. Two terns before graduation I noticed I only needed four more classes to get the sociology degree as well, so I took the classes.

- Exposure to the field through a family member.

- Fit will with my belief system.

- Because of finances, needed to graduate quickly. Changed major from business to sociology.

- At the time I began, while intending to be a Lutheran pastor, my counselor suggested sociology.

- At the time I wanted to change the world.

- Had planned to go for master's in social work. Became unrealistic goal.

- Because of my desire to work with people, especially kids and my interest in the relationship of people with each other and society.

- Was interested in being a social worker.

- My career choice was juvenile counseling; I had social work and psychology minors; I decided sociology would be a good base.

- Personal interest.

- Thought I'd be a social worker.

- I wasn't sure what I wanted to do in the future and I really enjoyed my sociology classes.

- I was in psychology and had major differences of opinion/philosophy with the department so I switched.

- I felt that upon graduation I would be working with people in some capacity so I felt the more I understood about people, the more successful I would be.

- Interested in subject and relationship to nursing.

- The subject matter was interesting and the professors were helpful and fellow students were great. 
Alumni Responses Regarding Why They Decided To Major In Sociology

- A desire to work with people.

- Personal interest. If I had it to do over, I would take something that led to a career. Never used sociology after 1971.

- I felt it would be helpful in all phases of my life.

- Interest in inner city/urban issues for my future career as and MD in under-served inner city areas.

- Wanted more perspective on society - groups, etc. not just psychology.

- It was undecided between sociology and psychology, but there was no speech class required for sociology - that was the deciding factor. Since then I have come to regard speech as critical.

- To eventually complete a master's degree in social work.

- I found it interesting; I enjoyed theory and felt what I learned had application in all aspects of my life, personal and professional.

- To learn how society works and its impact on the individual.

- Courses were interesting. Sociology seemed to be something that could be used in many different occupations leaving many options for the future.

- General interest and guidance from professors.

- I have always been interested in social class and gender and how it related to opportunities in society.

- It is a subject that has interested me for many years and as my college degree is a very personal life goal and not necessarily intended to further or create a career. I chose it for personal interest and knowledge.

- To help better understand the world.

- Thought I would have a better chance of being accepted into graduate school with a behavioral science degree. Sociology was the fastest route given previous course work.

- It seemed most fitting and helpful for me at the time where I could put it to use in my employment - I worked while in college. 


\section{Appendix D}

Alumni Responses Regarding Why They Decided To Major In Sociology

- I only needed five more classes to obtain a major in sociology. It complimented my major in Administration of Justice.

- I found it interesting and did well in it.

- Interested in studying group/urban dynamics.

- I thought the study of groups would help me understand my society.

- I wanted the best education possible in dealing with people since that is what makes up the world still at this point and time.

- Enjoyed the classes and wanted to get a four year degree.

- I love children and want to be in the social work profession helping them.

- Long time dream.

- Curiosity. I had hoped to figure out what was wrong with this great USA.

- I wanted to understand how social context influenced individual development.

- Found it to be what fascinates me.

- At the time I had in mind to be a welfare worker.

- Social groups, class and status, and group behavior held my interest.

- I don't remember.

- Liked the social sciences.

- Prepare for law school - I went to law school, hated it, quit...

- I like the classes - easy to relate to. Helped me in sales - understand the person across from me.

- I found it to be extremely fascinating and I want to be a hospital administrator and medical sociology class attracted to the department along with the statistics.

- Decided my last year to pick up the BS in sociology because I already was very close to the credits required for the degree. Also graduated with a BS in psychology and a BS in criminal justice at the same time. 


\section{Appendix D}

Alumni Responses Regarding Why They Decided To Major In Sociology

- My intent was to pursue an MSW. The year I applied to PSU the undergraduate social work program was canceled. I decided on sociology because I believed the course work to be similar and appropriate for the graduate program.

- Interest in he field from a theoretical viewpoint, only later realized few career opportunities outside of academia.

- I was interested in studying about society in general.

- Long term interest in social problems/issues, particularly ethnic relations. Interested in obtaining framework for promoting constructive social change.

- Because I like people and wanted to work with all kinds. Personnel management has always been my best asset. I get along with people and I am a good organizer.

- I wanted to "save the world"! 


\section{Appendix $\mathrm{E}$}

Courses Which Have Been Personally and Professionally Valuable To Alumni Since

Graudation

\section{Sociology Courses Which Have Been Personally Valuable To Alumni Since Graduation}

$\begin{array}{ll}\text { Sociology of Women } & 18 \\ 385 & 16 \\ \text { Theory } & 1 \\ \text { Minority Groups } & 1 \\ \text { Social Psychology } & 1 \\ \text { Deviancy } & 8 \\ \text { Marriage and Intimacy } & 8 \\ \text { Criminology } & 6 \\ \text { Social Change } & 4 \\ \text { 205/6 } & 3 \\ \text { Complex Organizations } & 3 \\ \text { Sociology of Aging } & 3 \\ \text { Sociology of the Family } & 3 \\ \text { Urbanization } & 3 \\ \text { Eastern European Societies } & 2 \\ \text { Insanity \& Femininity } & 2 \\ \text { Juvenile Delinquency } & 2 \\ \text { Revolution } & 2 \\ \text { Small Groups } & 2 \\ \text { Social Movements } & 2 \\ \text { Social Stratification } & 2 \\ \text { Sociology of Art } & 2 \\ \text { Death and Dying } & 1 \\ \text { Human Sexuality } & 1 \\ \text { Law Enforcement } & 1 \\ \text { Medical Sociology } & 1 \\ \text { Social Ecology } & 1 \\ \text { Sociology of Development } & 1 \\ \text { Sociology of Small Business } & 1 \\ \text { Urban Social Structures } & \end{array}$

\section{Sociology Courses Which Have Been Occupationally Valuable To Alumni Since Graduation}

$18 \quad 384 / 5$

16 Minority Groups 18

16 Social Psychology 17

15 Theory 16

$14204 / 5 \quad 11$

8 Criminology 11

8 Sociology of Women 11

6 Juvenile Delinquency 8

4 Medical sociology 6

3 Deviancy 5

3 Sociology of the Family 4

3 Complex Organizations 3

3 Demographics 3

3 Drugs in Society 3

2 Femininity \& Insanity 3

2 Group Behavior 3

2 Small Groups 3

2 Social Movements 3

2 Organizational Theory 2

2 Population 2

2 Social Change 2

2 Sociology of Alcohol 2

1 Stratification 2

Women \& Violence 2

Collective Behavior 1

Corrections Community 1

Future of society 1

Geriatrics 1

1 Historical Sociology 1

1 History of Social thought 1

Large Scale Institutions 1

Marriage and Intimacy 1

Political Sociology 1

Poverty 1

Power \& Inequality 1

Revolution 1

Sociology of Art 1

Sociology of Business 1

Sociology of Education 1

Sociology of Health and Illness 1

Sociology of Religion 1

Urban Gangs 1

Urbanization 1 


\section{Appendix F}

Suggestions for Improvement Made by Alumni and Current Students

\section{ALUMNI}

- Incentives for fieldwork.

- To combine a psychology degree with a sociology degree.

- My sociology classes were very very interesting - especially so since at that point in time social change was taking place before our very eyes, but they certainly didn't prepare me for any kind of "career" related to sociology.

- I've viewed the study of sociology primarily as a base on which to build a more specific study. Standing alone, most people will not be able to make it "work for them" but partnered with other learning I feel it can be extremely valuable.

- The program was good, especially the radical sociology, however, if I would have received counseling on what I wanted to do career wise, I would have changed. However, it was a good foundation for graduate school in social work.

- Increased emphasis on practical applications of the study of sociology to the world of work.

- Career planning.

- Orientation to sociology department.

- Job opportunities, graduate student options, etc., offered to newly registered sociology majors prior to beginning of first term.

- My personal feelings are that females were less challenged to speak out in class about their interpretations about coursework. Males were called upon and questioned about their opinions. Males were favored by faculty visiting casually with them, showing interest in their non-school work activities as well.

- Part of any teacher's efforts should be to assist the student in growing personally to feel his or her thoughts and contributions are valid, important, and worthwhile.

- Loved it!

- More hands-on study - practicum/internships.

- Why are you studying sociology - what are you going to with the degree?

- Judging from the tone of your questions, you seem very concerned with the utility of a sociology degree. Sociology is not business administration and it looses its essence if it gets too useful. The sociology stands the world on its ear and observes while the insights may prove useful, their value is the uniqueness of the experience. 


\section{Appendix F}

Suggestions for Improvement Made by Alumni and Current Students

- I feel there should be more interaction with possible employers.

- I believe all departments need to be more acutely aware of the needs of the various social service providers when they're preparing students to enter the job market. Fluency with various computer software systems is just as important as sociology courses.

- I found most of my professors in sociology to be theorists with little grasp of daily life and reality. At least one seemed to enjoy playing with students as though we were his experimental lab rats. A couple of professors taught useful information, such as research \& statistics. I hope for your sake that has changed.

- Most of what I studied has had little practical application to my work. I got more out of Toastmaster's and Kiwanis than several classes combined as far as day-to-day useful skills. Budget classes at a community college taught by someone who did it for a living still help me function. The same is true of computer skills.

- Please, more emphasis on sociology's application to career fields. Closer ties to downtown government and business. Relationships to other disciplines greater emphasis.

- Apply greater variety of software.

- It was an exciting time for me. Loved learning, playing with ideas, theory building, etc.

- More emphasis on applied skills.

- Professors should refrain from "academically distancing" themselves from students.

- Students pursuing degree in sociology should realize degree is not very marketable in "real life" - background in sociology may be fascinating, but it won't pay the bills.

- It has been 25 years since I graduated from the PSU department. I am grateful to this very day for the opportunity to have avoided the draft during the late 60's and have interesting subjects and professors to study. Also, having a great setting for protesting the war and meeting young women were definite plusses.

- Make sure professors are good teachers - to an undergraduate, that is all that matters - I had many professors who may have been first rate scientists - but they couldn't teach to save their lives.

- In my experience, only straight A students and graduate students were even noticed by the department - the rest of us just fell through the cracks. 


\section{Appendix F \\ Suggestions for Improvement Made by Alumni and Current Students}

- There was no preparation for life after graduation - you know - getting employment!!!

- Enforcing academic strength; the sociology department professors who were the best in their field seemed to draw much negative feedback from lazy and inept students. The entire department should have more consistent standards (high ones at that) for evaluation student performance.

- Add more classes dealing with vulnerable population i.e., women, children, etc.

- It is very important that the faculty be more involved in career pathways for students. The staff have great skills when it comes to teaching but they need to expand into the community and seek out areas that a sociology students can practice their new-found knowledge. They could also be better mentors for student. I received a letter of recommendation from a sociology teacher which had three misspellings - is this how we want to represent PSU?

- I thought the undergrad program was good except for the theory classes. They were a waste. They should be combined into one 471 course and briefly cover the material instead of making it such a big deal. Parts of it were interesting but not so much of it.

- Relate course work to work situations.

- Coordinate course work within the department.

- Institute internships.

- Coordinate internships with academic and community based leadership.

- Have guest speakers from the community.

- I enjoyed the sociology classes at PSU. I do feel I needed more information on what jobs I would be qualified for and job interview skills.

- I especially enjoyed my criminal justice classes.

- My major suggestion for PSU would be more accessible help with all of college - credits etc., needs and questions. I always felt no one was there to answer questions and felt they would send me in circles instead of helping. Better office procedures.

- I feel students need to know what types of jobs they are going to be qualified to fill and they need to know what is actually available in the job market.

- I'm too distant from it to know.

- Promote group study from the freshman year. 


\section{Appendix $F$ \\ Suggestions for Improvement Made by Alumni and Current Students}

- The courses were almost all far too easy to breeze through without learning/absorbing a thing. To learn and formulate opinions, the professors should treat the courses as college courses requiring college level work including research papers.

- Scantron in a 400 level class is such a joke.

- Not all of us are little socialist feminist crusaders. It is sad that $90 \%$ of my instructors represented only one mode of thinking.

- There was an attitude of superiority to the outside world, a feeling that the elite staff of the department was examining the world from up high. This was apparent with everything that they did and especially with their attitude toward the students. There seems to be very little self-examination in the department.

- More courses dealing with contemporary issues.

- Class schedules seemed to conflict for me. Many times it could take years to get into a class I needed because it was always available at the same time. More variety would be good here.

- Get professors that have interest in teaching and give those that don't the door!

- I have absolutely no regrets about my choice in majors. I am disappointed only with the current economic situation and the lack of opportunities even with a college degree.

- As incoming freshman, speak with advisors - which should be mandatory, organized, and more readily available.

- Department needs to create internships and/or build networks with community, leading to jobs or practical experience for graduate school.

- More practical application.

- Internships.

- More independent research - term papers dealing with current class areas of study.

- Integrate older students into classes.

- More "hands on" (practical) experience in the community to obtain personal experience in different employment settings.

- Career opportunities - avenues - should be discussed from the beginning. Following graduation, I spent years in employment, personnel and sales there was little available in my field that I considered a livable wage. 


\section{Appendix $F$}

Suggestions for Improvement Made by Alumni and Current Students

- Include grant writing - business management, social government, urban politics and etc. within the curriculum also training in presentations/public speaking.

- Based on pat experience, better career counseling would be useful to establish vocational application for the degree.

- There needs to be a balance between learning for the sake of learning and learning as preparation for a career.

- In no way was I prepared for a career.

- In the market place, my degree has meaning only as a BS. Any major would have provided that.

- My degree gave me no marketable skills.

- I was very satisfied with most of the instructors and classes in the PSU sociology department.

- Not enough writing experience.

- Fewer scantron tests.

- Class sizes too large, resulting in teachers lecturing about what would be on the test and regurgitation of memorized facts. Not an education by my standards.

- Suggest contemporary applications of sociology, rather than classes rehashing old (classical) theory.

- Virtually no advising offered or available to direct/assist students to a graduate program or a job or field which utilizes a sociology undergraduate degree.

- Faculty discontent and division in frustration. It would be easier on the students if there were less derision and more working together towards a common goal. It seems, sometimes, as though the student gets left in the dust of inner-office conflicts.

- Identify marketable skills.

- Tell the student that without experience, there are very few jobs for sociology students except for some areas of law enforcement.

- Would suggest heavy emphasis on classical theory, less emphasis on contemporary theory.

- More information on what you can do with a sociology degree - my choices were graduate school, to teach, or nothing. I went back to the career I had before getting my degree so other than an understanding of people in their environment, my degree did little for my career. 


\section{Appendix $F$}

Suggestions for Improvement Made by Alumni and Current Students

- Get professors that can convey more excitement to the students.

- Although I enjoy my sociology major, I felt it really did not help me get the type of position I wanted in the working world.

- More correlated courses within sociology, more theory work - Toth was the best professor in the department - he let us think for ourselves.

- More experimental learning, less formal lecturing.

- Less test taking, more critical writing.

- More experience with computers - especially with regards to operating statistical programs.

- Professors who are interested in encouraging students success who are willing to communicate to students that they (the students) matter.

- In my experience, most PSU sociology professors seem impersonal, detached, and uncaring both in and out of the classroom.

\section{CURRENT STUDENTS}

- I understand that there is pressure on all sociology instructors to grade on a strict bell curve. This means that the average student will get a " $\mathrm{C}$ " as their average grade. The problem with this is that a $\mathrm{C}$ average, or a $2.0 \mathrm{GPA}$, is a probation GPA. Does this mean that the "average" sociology major should be on probation? I disagree with curved grading because of the probation dilemma and because it creates an atmosphere of competition that discourages working and learning together.

- More staff, more internships or practicums, and more networking.

- The professor who comes to class so often drunk should not be allowed to grade students-he had no idea what he had said in class and seldom made more than one or two points - although he had at one time been very interesting, I'll bet.

- Less technical emphasis and more community involvement. To study the reality makes the textbook come alive and have meaning. Let each sociology student be required to study some aspect of society and write about it, applying information learned during the year, from having gone out into the community as well as into the library. 


\section{Appendix $F$}

Suggestions for Improvement Made by Alumni and Current Students

- Graduate students in the sociology department are graded unfairly. Although very popular, one of them was actually gained professorship really wasted valuable class discussions - his ego needed more to hear himself than did he value any comment or questions from students about married life during his marriage and intimacy class.

- More advising on careers after graduation various opportunities that are available where to go, how to go about finding something pertaining to sociology. Classes that offered credit for a volunteer type of course, getting involved with people or organizations what need help.

- As a full-time worker, I need to be able to complete my degree at night. As of now, this is not possible, so I am looking into other colleges.

- Advisors should help students evaluate whether or not they should take stats 244 before taking $384 / 5$ most students would greatly benefit from doing so.

- Somehow raise the academic rigor of the courses and the quality of instruction (I have a minor in anthropology and these factors in the anthropology department are as consistent as they are varied in the sociology department at PSU) some of the best as well as some of the worst instructors I have encountered in at PSU have been in the sociology department. I would wish that a university with an urban mission would be known for the excellence of its sociology department.

- Teachers should be more involved and creative instead of lecturing from the book only.

- More selection of courses dealing with social issues, current and past.

- Work experience, like a practicum from a choice of employers.

- More variety of instructors with different viewpoints.

- Feedback on evaluation of classes and instructors.

- More independent studies courses available.

- Courses valued in on or more different fields, gaining sociology credit besides.

- More papers and essay or take home tests. Less multiple choice tests-this is college after all. In the last four years the sociology department has decreased the type of classes and the times the classes are available. It made my last two years very difficult to take my soc classes that I needed to take. I don't think now that would major in sociology if I was an incoming freshman because of the selection of times and classes. I've also noticed fall offers classes that are great and by spring they offer nothing interesting for the upper division. I understand the budget issue, but as I said if I was an incoming freshman, I'd be really turned off. I might add that Dr. Toth was 


\section{Appendix F \\ Suggestions for Improvement Made by Alumni and Current Students}

my favorite sociology instructor and would highly recommend him to anyone who is a soc major.

- Please teach a curriculum that is adequate to today's world. Give students the opportunity to work in the different aspects of society (e.g. mental health, social psychology) more job experience (what is it that turns the students onfocus-being specific-go find their love).

- Better advising.

- Better preparation for graduate studies.

- Classes required for graduation (384/5 \& 471/2) not ever in years at PSU offered at night. Struggling to graduate with major in sociology.

- More course at various times instead of the shrinkage of choices I've recently seen.

- More female instructors.

- More practicums and or cooperative education with local businesses

- As far as my experience goes, I believe the department to be functioning well. I would suggest to advertise more jobs, internships, or scholarships available. Also, testing situations could be improved by adopting Dr. Toth's methods. It is much more difficult, however, I feel the extra work is worth the knowledge retained. I do realize that size of the classes does produce strains on this methods.

- Make the teachers more approachable

- My only suggestion is that more readily available information on jobs pertaining to sociology may be available to students.

- I am very satisfied with my experience in the sociology department - thanks.

- More evening classes that are conducive to a 40 hour work week for people like myself who can only attend at night.

- I feel that the program is fundamentally sound, however, some interdisciplinary subjects help clarify sociological trends. For instance, in the Human Relations track, mention is often made of the effects of the industrialization on the American Family, but that was not clearly illustrate to me until I took "History of the American Family" through the history department. The study of sociology is affected by all areas of social sciences. I would like to see these areas merge more - similar to an American studies perspective.

- More contact with professors as in department get togethers. More assistance with scheduling/advising. I would love help with practicums and department initiated internships. As a senior, I worry about what kind of job I will be 


\section{Appendix F}

Suggestions for Improvement Made by Alumni and Current Students

able to get with my bachelor's degree. I thoroughly enjoy Kathy Farr, Bob Liebman, and Michael Toth. These three professors are in no way "easy" they make you feel human and not like an idiot.

- Experience with computers and learning what jobs and internships are available and be placed with that business for credits, need to be brought into the department. That is what I needed earlier.

- PSU needs to find out the overall computer usage in the local area and those areas where PSU graduates are hired. The U needs to have a drop-in basis, tutor program on the widely used computer equipment and software. I've already lost out on a few job opportunities due to the lack of skills on Mac, IBM, basic functions. I really like class lecture format yet absolutely regret not have user-friendly computer workshops to attend. The form computer classes scared me off.

- Before students major in sociology, they should understand the limited score of its usefulness in employability. There is little advising available, and even worse, students must initially pick an advisor. How about having sociology advisors assigned when students select the sociology major, and have an oncall advisor for drop ins? A student cannot say "I'm interested in sociology urban planning, how do I maximize my training? Without getting a blank stare and uninformed answer.

- Offer more classes.

- It would be nice to hear what, specifically, a person can do job-wise within he field of sociology during class time. For example, a class like sociology of deviancy could give us a general idea (or a specific idea, for that matter) of the kinds of jobs available in the field of sociology.

- Possibly to be greeted/welcomed into the department by something other than a survey. Spring term was my fist term back in school. I had only one sociology course and, unfortunately, a terrible professor. I did not feel much a part of the department. I'm still too new to offer many useful suggestions and do appreciate the opportunity to participate in this survey. I understand there are some excellent professors and look forward to fall term. It is especially important to be able to come up with a full schedule of classes without requiring a trip to Portland every week day - I live approximately 40 miles away and hope to be efficient about community.

- More 400 level classes! More professors like Kathy Farr and Laurie Skokan. New sociology majors should be assigned an advisor.

- During the introductory session, the sociology major should be assigned an adviser whom they will become familiar with during the course of their 


\section{Appendix $F$ \\ Suggestions for Improvement Made by Alumni and Current Students}

studies. The new Freshman Inquiry should have been implemented sooner its nice having a coherent curriculum. An idea a long time coming.

- I am so glad that there is a survey in the sociology department that could reflect our ideas and opinions. I enjoy my school life in PSU, but I have some experiences that I would like to share with you:

- Sometimes, I think it is unfair for graduate and undergraduate to attend in the same class although they have different passing mark. If the class requires a term paper, the graduate would write $20 \%$ more than us. I've attended one class without any term paper. It means it only depends on the 10 points difference. I also found out (and other undergrad in the same class) that the class requirement, teaching technique and the book content are harder for the undergrad than the classes only for junior/senior. It is not appropriate for grad and undergrad to be in the same class.

- As a whole, I have enough time to do the reading but in some classes, I could hardly catch up. I wonder if the sociology department has a standard of reading in each class.

- When I first came to PSU, I had Mary Lee as my counselor. Recently, I went to have a counselor to check over my subjects before I graduate. The staff over there says Mary Lee worked in the graduate School of Social Work and there is no counselor in the sociology department. I am advised that every teacher could be my counselor. I do so, but some teachers do not know about the details in the department and some other questions, too.

- Better student-staff ratio.

- More instructors.

- I recently graduated with a BS in speech communication and a minor in sociology. My sociology classes were unrelated and could have used more guidance. I was not impressed with the sociology department's advising method because it lacked a personal touch. I would like the sociology department to pay more attention to communication skills. For example, a good interviewer could find a lot of information. Sociologists would also benefit from group communication, intercultural communications and interpersonal communication. Learning how people communicate explains a lot about how they behave (and behavior influences communication). Communication courses could also help explain how to recognize biases!

- While the information presented in class is usually from cases studies (vs. abstract) I would prefer a more hands on approach.

- I have really enjoyed the sociology classes I've taken at PSU. My only complaint was my Soc. 205 professor. 


\section{Appendix $F$}

Suggestions for Improvement Made by Alumni and Current Students

- If the university is going to invest in program of study they should make it possible for students to get the classes they need. Example: Soc. 384 is only offered once winter and spring term and is held in a very small room. This is a required class and needs at least one additional section per term.

- A counselor in the department to answer questions. Instructors do not have a lot of the knowledge need to answer our questions. Things like future jobs or graduate school are not familiar topics to them it often seems.

- The program is OK, but class sizes are too large and there was too little student to student and student to instructor interaction. For this reason I left PSU after on year and went to Marylhurst College instead. More expensive, but no class over 30 students and a great deal of experimental work. Graduated June 1994-double major-sociology \& psychology.

- Get rid of the liberal deadwood instructors.

- Get more qualified teachers and teach more straightforward, applied classes.

- Develop it so that if one desires to continue in sociology in graduate school, the option for a masters degree is available for social work. Offer chances for career moves to those serious about a sociology career.

- Make course requirements more readily known. Track graduation more carefully.

- Overall I feel that this is an excellent program. The only problem (or the main one) is trying to keep professors focused instead of being completely side-tracked by students asking stupid questions or making inflammatory comments. Many courses' content seem to be compromised by that tendency.

- I think that there needs to be more access to internship and practical experience. I would like the opportunity to learn to put the knowledge I have learned to work. I am not in a position to apply my knowledge. I do not feel I have received much guidance in my pursuit. 